\title{
An assessment of the Zimbabwe National Family Planning Council's community based distribution programme
}

Baker Ndugga Maggwa

lan Askew

Population Council

Caroline S. Marangwanda

Ronika Nyakauru

Barbara Janowitz

Follow this and additional works at: https://knowledgecommons.popcouncil.org/departments_sbsr-rh

Part of the Demography, Population, and Ecology Commons, International Public Health Commons, Maternal and Child Health Commons, and the Public Health Education and Promotion Commons How does access to this work benefit you? Let us know!

\section{Recommended Citation}

Maggwa, Baker Ndugga, lan Askew, Caroline S. Marangwanda, Ronika Nyakauru, and Barbara Janowitz. 2001. "An assessment of the Zimbabwe National Family Planning Council's community based distribution programme," FRONTIERS Final Report. Nairobi: Population Council. 


\section{An Assessment of the Zimbabwe National Family Planning Council's Community Based Distribution Programme}

\section{Population Council}

Baker Ndugga Maggwa

Ian Askew

\section{Zimbabwe National Family Planning Council}

Caroline S. Marangwanda

Ronika Nyakauru

\section{Family Health International}

Barbara Janowitz 


\section{SUMMARY}

Since its inception, the Zimbabwe National Family Planning Council's (ZNFPC) Community Based Distribution (CBD) programme has made significant and well-documented contributions to the demand for and use of family planning in Zimbabwe. Data from several studies have shown, however, a steady decline in this contribution and that the CBD agents spend more time re-supplying existing clients than recruiting new acceptors. Moreover, the CBD programme needs urgently to be able to address the AIDS crisis in the country. ZNFPC has undertaken this review to guide it in making appropriate decisions about the future direction for the programme.

Data were collected through a review of documents, in-depth interviews with key staff at headquarters and provincial levels, interviews with 128 CBDs, 37 Group Leaders, 33 Community Leaders, 23 Environmental Health Technicians, 40 Clinic Nurses, 19 District Nursing Officers and 22 Community Health Nurses, and through sixty-one focus group discussions with different groups of community members.

The review confirmed that the number of pill clients served and Couple Years of Protection (CYPs) provided has been steadily declining since 1987. However, these performance measures do not take into account the client contacts undertaken or the non-family planning information and services offered by CBD agents. Several potential reasons for the declining performance were identified. There are now many alternative sources for family planning that compete with the CBD agents for clients. Moreover, the proportion of women wanting to use the injectable has increased, putting the agents at a disadvantage compared with clinics. The average age of the CBDs is over 40 years and many are finding it difficult to cover their catchment areas effectively and to reach younger clients.

Clients served by the CBDs were satisfied with the services received. They particularly appreciated the privacy associated with home visits. Clients also mentioned that CBDs had more time to listen to them, and were a more regular supply of pills and condoms than the clinics. Relationships between the CBDs and the Ministry of Health and Child Welfare $(\mathrm{MOH} \& \mathrm{CW})$ clinics are an ad hoc arrangement and a more formalised arrangement could help to ensure a smoother liaison between the two.

On average, in 1999, each client visit cost Zimbabwe Dollars (Z\$) 108 (US\$6.00), and each CYP provided cost Z\$299 (US\$16.61). ZNFPC is recovering up to 16.4 percent of its programme costs through sales of contraceptive pills, but there are many problems with the management of the cost recovery programme. A price and demand elasticity study would enable ZNFPC to find the highest prices that can be charged for each service without losing too many clients. ZNFPC needs to also reduce its programme-operating costs (while not reducing the outputs produced) through reviewing the terms of service for CBDs and Group Leaders.

Broadening the role of the CBDs was recommended as a way of making agents more productive and the programme more efficient. Some activities felt to be acceptable and feasible include: providing more detailed information on STIs/HIV/AIDS; identifying and referring individuals with STI symptoms for diagnosis and treatment at clinics; providing supportive counselling to people living with HIV/AIDS; educating communities about HIV Voluntary Counselling and Testing services and motivating their use; providing on-going 
supportive counselling after HIV VCT testing; assisting parents to better communicate with their children on sexual and reproductive health issues; and advising adolescents like surrogate aunts and uncles.

There appears to be a mismatch between the skills available and the staff roles at various levels of the programme, particularly for the Sister in-Charge-Community (SICC) and the Group Leaders. It was recommended that ZNFPC review its recruitment criteria to ensure that those individuals with the appropriate training and skills are hired for the different roles and responsibilities. For those already employed, it was recommended that the ZNFPC seek ways of increasing their skills so that they can fulfil all their responsibilities.

ZNFPC and the USAID Mission have used the results from this study to plan for revising the programme so that CBDs have a broader range of responsibilities and the structure is modified to become more efficient. Agents will be expected to actively seek adolescents and men in their communities to offer them information about the full range of contraceptives, with an emphasis on condom promotion. They will also be trained to provide more education, especially to men, on STI/HIV risk reduction behaviours, symptoms of STIs, and appropriate health-seeking behaviour when symptoms are suspected. Where available in the vicinity, VCT for HIV will be promoted and supported. CBDs will also be trained to give information on antenatal and postnatal care, to refer for infertility counselling, to refer for post abortion care, and to give information about reproductive tract cancers and counselling for menopause.

To achieve such a major change in the role of CBDs, ZNFPC will undertake a major revision of the CBD programme structure to address the weaknesses identified in this review. In addition to substantial refresher and update training, this will include revising the terms of employment for agents, widening the use of depot-holders to work in conjunction with regular agents, improving linkages with MOH\&CW clinics, improving contraceptive supply logistics, and revising the MIS and monitoring and evaluation procedures so that the programme's performance is fully measured in terms of this range of reproductive health activities. Underlying all changes will be a search for ways to ensure that costs are reduced and productivity improved. 


\section{TABLE OF CONTENTS}

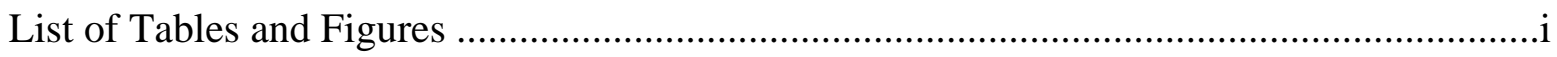

List of Abbreviations ......................................................................................................

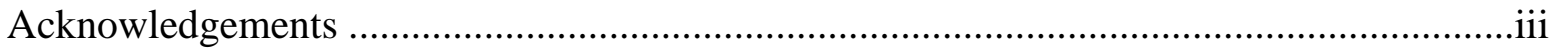

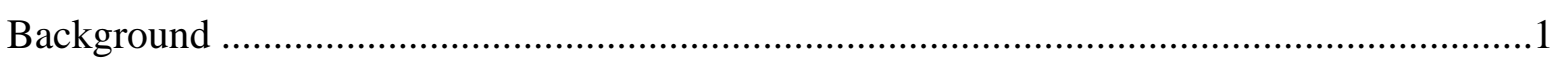

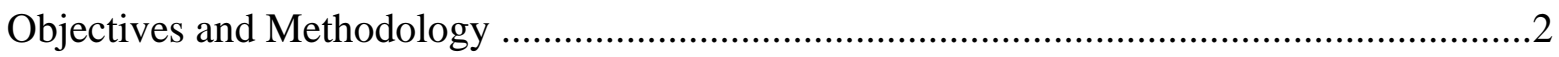

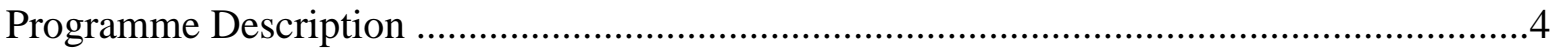

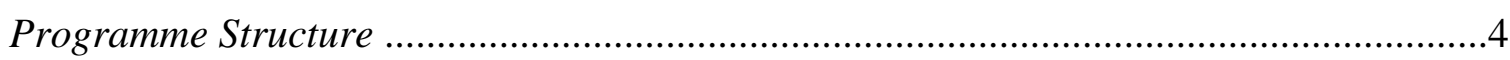

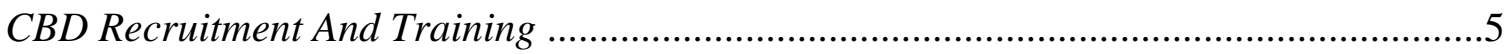

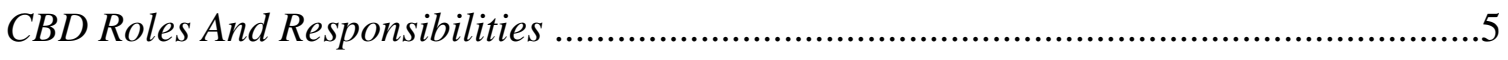

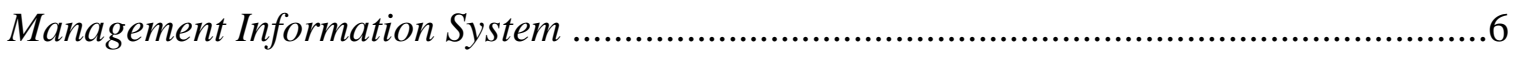

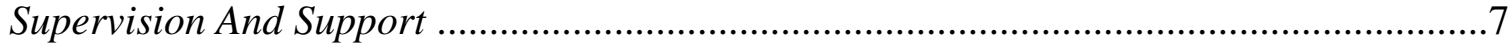

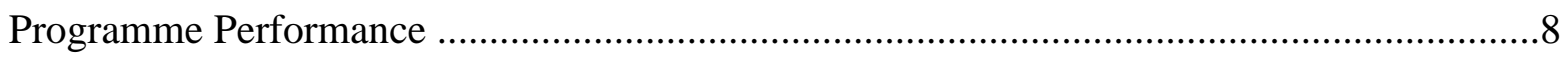

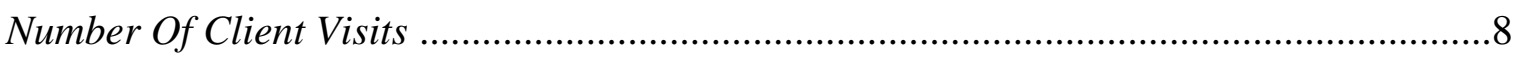

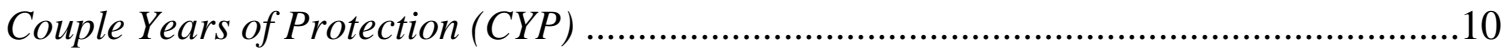

Possible Reasons For Declining Performance ................................................................ 11

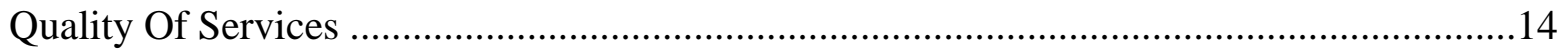

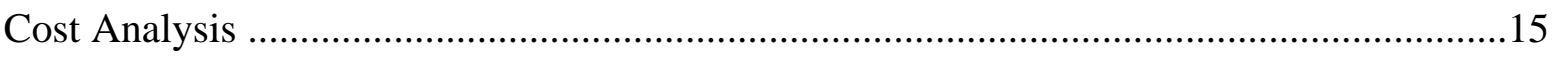

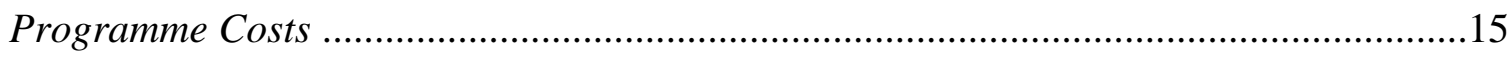

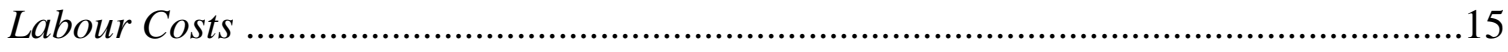

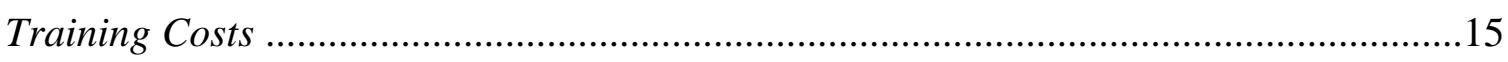

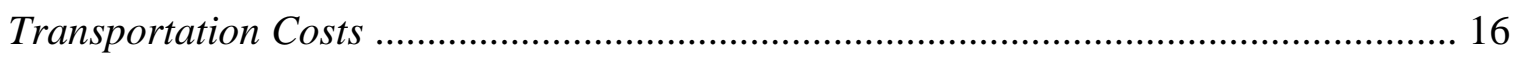

Contraceptive Commodity Costs ...................................................................................... 17

Distribution Of Costs By Component .......................................................................... 17

Average Costs Per Visit And Per CYP .......................................................................... 18

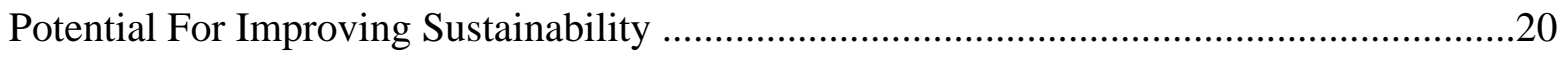

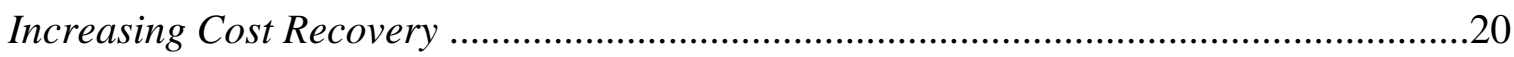

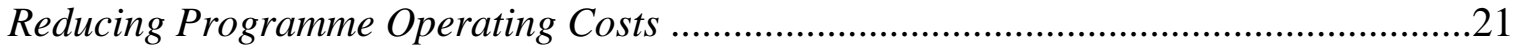

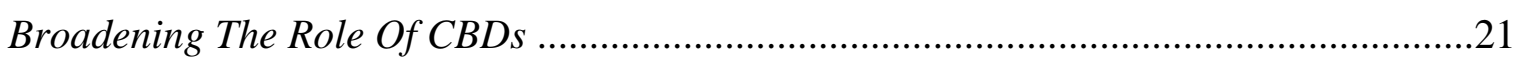

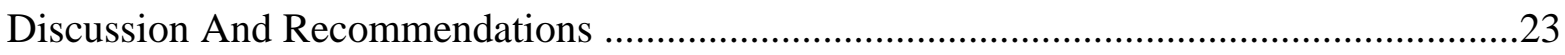

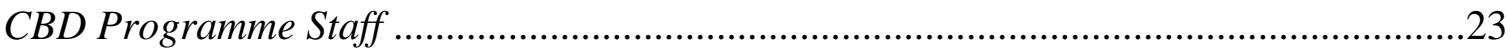

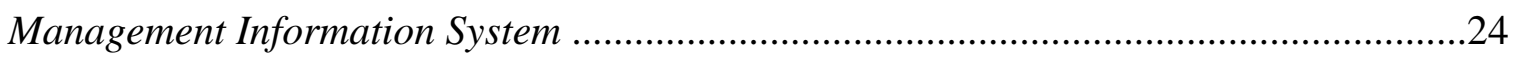

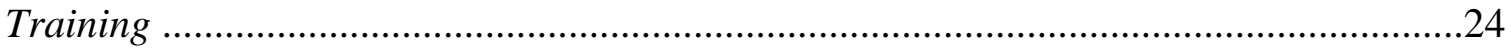

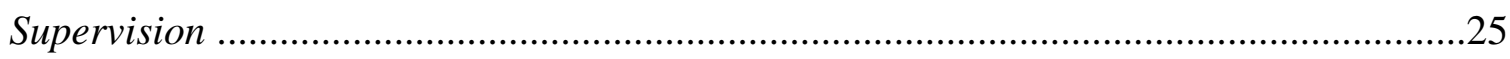

Relationship Between The CBD Programme And The $M O H \& C W$................................26

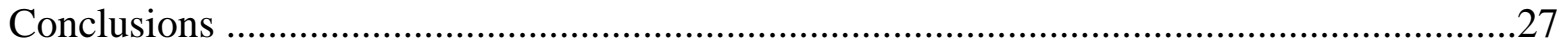

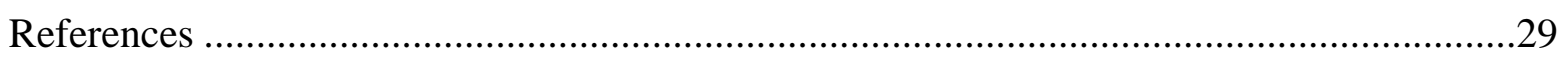

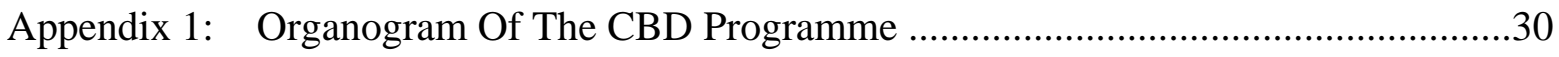

Appendix 2: $\quad$ List of people contacted ...................................................................... 


\section{LIST OF TABLES AND FIGURES}

Table $1 \quad$ Number of CBDs by province and sex (1999) …........................................

Table 2 Annualised Costs for Training of CBDs and Group Leaders .........................16

Table 3 Average cost (Z\$) per pill client visit and per CYP by province (1998) ........19

Table 4 Average revenue generated per CBD by sex and by province (1999) ...........20

Figure 1 Total number of new pill acceptors per year for the CBD programme ............8

Figure 2 Total number of pill re-supply visits made per year ....................................9

Figure 3 Average number of pill-related visits per CBD by province (1998) ..............9

Figure $4 \quad$ Couple Years of Protection generated per year ….......................................10

Figure $5 \quad$ Average Numbers of CYPs per CBD by province (1998) .............................11

Figure 6 Distribution of labour costs by personnel category ....................................15

Figure $7 \quad$ Transport Costs for CBD Programme …..................................................17

Figure $8 \quad$ Total Costs of the CBD Programme (Zimbabwe Dollars) ….........................18 


\section{LIST OF ABBREVIATIONS}

\begin{tabular}{|c|c|c|}
\hline AIDS & - & Acquired Immune Deficiency Syndrome \\
\hline CBD & - & Community Based Distributor \\
\hline CYP & - & Couple Years of Protection \\
\hline DHT & - & District Health Team \\
\hline DHS & - & Demographic and Health Surveys \\
\hline EHT & - & Environmental Health Technician \\
\hline ERU & - & Evaluation and Research Unit \\
\hline FGD & - & Focus Group Discussion \\
\hline FHW & - & Farm Health Worker \\
\hline FPA & - & Family Planning Association \\
\hline FPAR & - & Family Planning Association of Rhodesia \\
\hline GL & - & Group Leader \\
\hline GoZ & - & Government of Zimbabwe \\
\hline HIV & - & Human Immune Deficiency Virus \\
\hline IEC & - & Information, Education and Communication \\
\hline MIS & - & Management Information System \\
\hline $\mathrm{MOH} \& \mathrm{CW}$ & - & Ministry of Health and Child Welfare \\
\hline PHT & - & Provincial Health Team \\
\hline PM & - & Provincial Manager \\
\hline PSZ & - & Population Services Zimbabwe \\
\hline RHC & - & Rural Health Centre \\
\hline $\mathrm{SDC}$ & - & Service Delivery Co-ordinator \\
\hline SDU & - & Service Delivery Unit \\
\hline SICC & - & Sister-In-Charge Community \\
\hline STIs & - & Sexually Transmitted Infections \\
\hline VCT & - & Voluntary Counselling and Testing for people with AIDS \\
\hline VCW & - & Village Community Worker \\
\hline VHW & - & Village Health Worker \\
\hline ZDHS & - & Zimbabwe Demographic and Health Survey \\
\hline ZNFPC & - & Zimbabwe National Family Planning Council \\
\hline
\end{tabular}




\section{ACKNOWLEDGEMENTS}

This study was undertaken with substantial support from many people whose assistance is gratefully acknowledged. At the Zimbabwe National Family Planning Council, special thanks go to the Executive Director Mr Godfrey Tinarwo, during whose tenure of office this study took place, the staff from the various units at the headquarters, the Provincial Staff, the CBDs and their supervisors, the donors and other stakeholders and the clients who agreed to participate in the study for all the support they gave to the study team. Special thanks also go to Dr K. Shodu, Director of the MCH/FP Unit at the Ministry of Health and Child Welfare, for all the support and guidance they provided to the study team during the design and implementation of the study activities. Special mention must be made of Ms. Roxana Rogers and Dr. Patrick Osewe of the USAID mission for all the technical and logistic support they provided to the study team. At the Population Council, special thanks go to Ms. Monica Wanjiru (Communication Specialist), Joanne Lewa and Violet Bukusi (Administrative Assistants) for editing and formatting the report. 


\section{BACKGROUND}

Modern family planning services were introduced in Zimbabwe in 1953, although, it was not until 1965 that the Family Planning Association of Rhodesia (FPAR) was established. Prior to gaining political independence, indigenous African politicians perceived family planning as a strategy used by the European settlers to reduce the African population while increasing their own, and so were not in favour of the family planning programme. However, after gaining political independence in 1980, the Government of Zimbabwe (GoZ) took over the FPAR and, in 1984, transformed it into a parastatal organisation under the Ministry of Health and Child Welfare (MOH\&CW), renaming it the Zimbabwe National Family Planning Council (ZNFPC). The ZNFPC is responsible for guiding family planning policy development on behalf of the $\mathrm{MOH} \& \mathrm{CW}$.

In addition, the ZNFPC also implements two nation-wide service delivery programmes: the Community-Based Distribution (CBD) programme, and a small number of fixed and mobile family planning clinics. The FPAR had established a community-based family planning programme in 1967, with a view to providing safe, low-cost and effective family planning services in both urban and rural areas. The first community-based agents to be recruited were five men known as Field Educators, whose primary role, until 1976, was to educate, motivate and refer clients to clinics for contraceptive services. This programme expanded rapidly after the creation of the ZNFPC, having over 800 CBDs nation-wide.

Since its inception, the ZNFPC CBD programme has made significant and well-documented contributions to the demand for and use of family planning in Zimbabwe. Data from Demographic and Health Surveys (DHS) have shown, however, a steady decline in this contribution in recent years. Furthermore, Situation Analysis studies conducted in 1991 and 1996 have shown that the CBDs spend much more of their time re-supplying existing clients than recruiting new acceptors.

The ZNFPC currently faces several inter-related problems concerning its CBD programme. First, there is a pressing need to review its service delivery role given the changes in the nature of demand for family planning services, and the pressing need for the programme to address the already huge and rapidly growing HIV epidemic. Second, despite the tremendous achievements in increasing contraceptive prevalence, condom use remains low ( 2.4 percent of both married and unmarried women, 14 percent for all men and 6 percent for married men). Increasing condom use is seen as essential given the high prevalence of HIV/AIDS in Zimbabwe, and ZNFPC needs to develop a strategy of using CBDs to promote the concept of dual protection and dual method use.

The ZNFPC also needs to improve the effectiveness of its STI prevention and management strategy as one means for addressing HIV/AIDS. To date, its efforts are concentrated on interventions directed to women considered at lower risk and primarily in clinical settings. The results from a recent OR study (Maggwa et al, 1999) show that this strategy does not function as effectively as had been hoped. On the other hand, there is now consensus that efforts to target men with both preventive messages and with services to treat established STIs is an effective strategy for reducing both the prevalence and transmission of STIs, including HIV.

However, ZNFPC's CBD programme has traditionally focused on reaching older and married women. One of the reasons why it has been able to do this successfully is because it has 
recruited and trained mainly (although not exclusively) older, female CBDs, and has explicitly encouraged them to focus their efforts on reaching women. Whether its CBDs can be reoriented to also reach men and the youth with family planning information and services, messages about STI prevention, and whether they can also identify and refer for treatment those men with a urethral discharge is not known.

ZNFPC is also being asked by the MOH\&CW and donors to explore the potential of its agents to fulfil the role of lay counsellors, sources of information and services, and referral agents for AIDS-related services, and especially for Voluntary Counselling and Testing (VCT). Whether the CBDs can be trained in these skills and fulfil this function is also unknown.

Moreover, with the gradual reduction in support from other stakeholders, the ZNFPC has introduced cost-sharing and other cost-recovery strategies that include paying for family planning consultations and the contraceptives themselves. ZNFPC needs to determine the potential for broadening the role of the CBD programme so that it increases overall productivity, but within the existing budget and without reducing the quantity and quality of family planning services provided.

Given the pressing and multi-faceted nature of these problems, and the need to develop and introduce innovative yet appropriate solutions to address them, the ZNFPC has undertaken this review to obtain information for guidance in making appropriate decisions about the future direction for the CBD programme.

\section{OBJECTIVES AND METHODOLOGY}

The overall goal of this study is to assist the ZNFPC in determining the future direction for the CBD programme given the changing reproductive health need in the country. The study objectives were to:

- Document the performance of the CBD programme

- Determine the costs of operating the CBD programme

- Determine the potential for financial sustainability of the CBD programme

- Identify the challenges and/or constraints affecting the CBD programme

- Recommend strategies for making the CBD programme more cost-effective and sustainable.

Data were collected through several methods. Relevant documents at the headquarters were reviewed, including service statistics, personnel policies, and programme accounts. All Sisters-in-Charge (Community), Service Delivery Coordinators (SDCs), Provincial Managers (PMs), and Managers at the Head Office were interviewed. In addition, all Provincial Medical Directors and Provincial Nursing Officers of the MOH\&CW were interviewed.

Structured individual interviews were conducted with 128 CBDs, 37 Group Leaders, 33 Community Leaders, 23 Environmental Health Technicians, 40 Clinic Nurses, 19 District Nursing Officers and 22 Community Health Nurses. Selection procedures for sampling these respondents were as follows. 
Five Group Leaders were randomly selected from each of the eight provinces of Zimbabwe. Thereafter, the CBDs supervised by these 40 Group Leaders were grouped into three categories on the basis of their performance. A composite measure was derived from the number of Couple Years of Protection (CYP) generated and revenue collected by each CBD to classify them into high, medium and poor performing categories. For each Group Leader, one CBD was randomly selected from the high, medium and low performing groups. The exception to this procedure was the city of Bulawayo where all CBDs were included. A total of $128 \mathrm{CBDs}$ were selected using this procedure.

In each district where a Group Leader was selected for the study, a list of clinics used by the CBD programme as referral centres was developed and one clinic randomly selected. At each of the selected clinics, the nurse in-charge was interviewed and, where available, the Environmental Health Technician (EHT). In addition, all District Nursing Officers in the participating districts who were available during the day of the visit were interviewed.

Information was also collected through sixty-one focus group discussions (FGDs) with the following groups:

- Female clients of CBDs (15 groups)

- Men, both users and non-users of contraception (15 groups)

- Female non-users of contraception (7 groups)

- Female youth (15-20 years) (8 groups)

- Male youth (15-20 years) (8 groups)

- Current female contraceptive users who are in an area that used to have a CBD but no longer has one (8 groups).

Sampling for participants in the FGDs was opportunistic. On arriving in an area whose CBD Group Leader had been selected for inclusion, all eligible persons for the different FGD groups were asked if they were willing to participate. A community leader in each area was also conveniently sampled for an in-depth interview.

For all groups or individuals interviewed, informed consent was obtained before the interview. For the service providers, CBDs and supervisors consent was obtained at two levels. First, overall consent was obtained from the managing director for the staff to be interviewed and then, each staff member was asked for individual consent before the interview. For the FGDs, the group was first explained the purpose of the FGD and requested for consent before the FGDs started. 


\section{PROGRAMME DESCRIPTION}

\section{Programme Structure}

The CBD programme has a hierarchical structure (Appendix 1), headed by an Assistant Director (Service Delivery) who is based at the Head Office. The Service Delivery Manager, who is also based at the Head Office, assists the Assistant Director. A Provincial Manager has overall responsibility for the CBD programme in each province, and informs the Service Delivery Manager about progress and problems that need their technical input. Most Provincial Managers do not have a clinical background, a role that is filled by a Service Delivery Coordinator (SDC) who is usually a nurse midwife. The SDC supervises the clinicbased programme activities and is also the immediate supervisor of the Sister-In-Charge Community (SICC) who is a nurse with post-graduate training in community nursing and responsible for supervising the CBD Group Leaders (GL). At the district level, a GL is responsible for supervision of the day-to-day activities of approximately ten CBDs.

The programme currently has 571 active CBDs, although this is a recent reduction from the 800 or so agents the programme used to employ in the early 1990s. Almost three-quarters $(71 \%)$ are women and in all provinces female CBDs outnumber males (Table 1). The majority of the CBDs (68\%) have worked for the ZNFPC for over thirteen years - only 12 percent have worked for less than six years. The mean age for the CBDs is 43 years with a range of 39-46 years. Most CBDs have low levels of education - one-half of the 125 CBDs interviewed had attained primary level of education, 22 percent had two years of secondary education, and only 22 percent had completed four years of secondary education.

Table $1 \quad$ Number of CBDs by province and sex (1999)

\begin{tabular}{|l|c|c|c|}
\hline Province & Male & Female & Total \\
\hline Masvingo & 19 & 72 & 91 \\
\hline Manicaland & 21 & 67 & 88 \\
\hline Mashonaland East & 22 & 60 & 82 \\
\hline Midlands & 20 & 53 & 73 \\
\hline Matabeleland North & 23 & 48 & 71 \\
\hline Matabeleland South & 19 & 44 & 63 \\
\hline Mashonaland West & 20 & 37 & 57 \\
\hline Mashonaland Central & 20 & 26 & 46 \\
\hline National Total & 164 & 407 & 571 \\
\hline
\end{tabular}




\section{CBD Recruitment And Training}

When first introducing the programme the community leadership, with assistance from MOH\&CW and ZNFPC staff, identified the areas where a CBD could operate. Poor access to a fixed public health facility that provides family planning services was the major criterion. Each CBD covers a catchment area of between 15 and 20 kilometre radius. These areas appear to be too large, however, given that the means of transport provided is a bicycle and most CBDs are over 40 years old.

Most catchment areas were defined more than ten years ago and ZNFPC has not reviewed them since. Many catchment areas no longer bear any relationship to the population settlement patterns or the current availability of family planning services. Many public health facilities have been built over the past decade and several other private sources of family planning services have been established.

Community leaders are requested by ZNFPC to identify and select three potential candidates at a public meeting. The selection criteria currently used by the community and ZNFPC are:

- Between 25 to 40 years of age

- Have at least 7 years of formal education (This was changed to at least 2 years of secondary education in 1995)

- Be proficient in English and one of the vernacular language (Ndebele or Shona)

- Be respected in the community

- Have positive attitudes towards family planning

- Be married.

The three candidates are then sent to the ZNFPC Provincial office, which will assess their aptitude and physical fitness, select one as the agent, and send this person for training. CBDs attend a six-week basic training course. The course includes motivation of clients for family planning services; supplying pills for contraception, supplying condoms for contraception and STI/HIV prevention; referring clients for clinical family planning methods; record keeping; interpersonal communication; and group talks.

Unlike virtually every other CBD programme in the region, ZNFPC's agents are employed as fulltime, salaried and pensionable employees after a period of probation.

\section{CBD Roles And Responsibilities}

The principal roles of the CBDs are to educate, motivate and supply condoms, oral contraceptives and spermicides to women and men in their catchment areas. They also provide information about all contraceptive methods available and refer clients to clinics and/ or hospitals for physical examination, management of method related problems and other methods.

The CBDs make visits to households within the catchment areas, discuss family planning with men and women through group talks, and also distribute information, education and communication (IEC) materials. Some CBDs visit schools and talk about responsible parenthood and safe sex. 
The CBDs are also expected to undertake other Primary Health Care activities. These include: advising communities on personal hygiene and sanitation; encouraging mothers to take their under-five children for immunisation; and teaching mothers how to prepare salt and sugar solution for managing childhood dehydration due to diarrhea.

More recently, the CBDs have been expected to provide men and women with information about the prevention of STIs and HIV/AIDS. In addition, some CBDs provide supportive counselling for home-based care for people living with HIV/AIDS. Although ZNFPC did not train the CBDs to do this, some said that they found themselves getting involved because many of those living with HIV/AIDS were also their family planning clients or relatives of these clients. Their communities view CBDs as sources of general health care, and so are expected to fill any gaps in the health care delivery systems. However, their roles in homebased care are neither standardised nor clearly defined and the CBDs have not been trained in providing care.

\section{Management Information System}

The CBD programme has an elaborate management information system (MIS) that requires the CBD to keep and prepare several records including:

- A Daily Work Programme Record Book: This is a record of their daily activities. The CBD records the registration of the clients, name, address, type of client (new or revisit), marital status, reason for contact with client, assessments undertaken, method and amount issued and notes whether the client was referred to a health facility for other services.

- Client Record Card: Each client attended by the CBD is issued with a card which has information on dates the client was attended to, methods prescribed, amounts of method issued, date due for next visit, blood pressure and weight measurements.

- CBD Service Monitoring Form: This form is completed on a monthly basis using information from the daily work-programme record book. The summary information on this form includes types of clients attended (new/revisit), quantity of each method issued, number of clients referred for long-term or permanent methods, examinations and problems. This form is used by the GL to check on the CBDs' performance and for self-evaluation by the CBDs.

- CBD Quarterly Contraceptive Stock And Revenue Form: This form allows the CBD to summarise the contraceptive stocks received during the quarter, stocks issued, balances at hand, quantities required for next quarter, contraceptive free issues and sales.

The key programme performance indicators are: new acceptors recruited; revisits attended; and CYPs generated. Information on these indicators is obtained from the CBD service monitoring and the CBD quarterly contraceptive stock and revenue forms. Copies of these forms are sent to the ERU at headquarters for further analysis and processing. The ERU uses the information to prepare annual reports, but rarely provides feedback to the field on a quarterly basis as is expected. The Group Leader compiles the information from all her CBDs and sends the form to the provincial office for onward transmission to the Head Office. 
Although CBDs are expected to give information and counsel clients on several reproductive health and primary health issues, the MIS does not monitor the CBDs' performance for these tasks. Given the current breadth of roles fulfilled, and ZNFPC's interest in including even more activities to address HIV/AIDS, there is clearly a need to review and revise the MIS.

The CBDs are expected to keep adequate stocks of the different oral contraceptive pills and condoms to last at least three months. The quantities required by each CBD are determined using the CBD quarterly contraceptive stock and revenue forms. At the end of each quarter, the CBDs meet with their Group Leaders who review their service statistics and physically count the stocks held by the CBD.

\section{Supervision And Support}

The GLs are responsible for monitoring and supervising between eight and twelve CBDs. Two types of supervision formats are used by the GLs to supervise CBDs:

- Spot Checks: These are visits by GLs to CBDs without prior notification. A spot check can take up to three days, during which the GL checks whether the CBD is following her/his work programme, checks the record books for accuracy and validity, and checks the contraceptive stocks and revenue collected. Spot checks provide an opportunity for the GL to provide immediate feedback to the CBD regarding her/his performance.

- Full Support Visit: Full support visits are planned in advance by the GL and CBD, and can last for five days. This type of visit is intended to address weaknesses identified during a spot check. During this visit, the GL works with the CBD to identify weaknesses and challenges and provide solutions. The visit is not a faultfinding mission, but for facilitative supervision.

Another supervisory mechanism is through the regular quarterly re-stocking meetings between CBDs, GLs and SICC, when supervisors update CBDs on both administrative and technical issues, and replenish contraceptive stocks and IEC materials.

Non-medical personnel in Zimbabwe are normally not allowed to prescribe and dispense contraceptive pills. As a precondition to allowing CBDs to dispense oral contraceptive pills, the Government of Zimbabwe required that the CBD programme must have a strong medical back-up system to handle referrals, side effects and contraceptive method-related complications arising out of the CBDs work. The technical support requirement for CBDs to be allowed to prescribe and dispense contraception was granted on condition that the ZNFPC employs a technical person i.e. the SICC to supervise the technical aspects in the program in addition to the establishment of referral linkages with local health centres. 


\section{PROGRAMME PERFORMANCE}

\section{Number Of Client Visits}

The average number of visits undertaken by a CBD was used as one measure of programme performance. This information was abstracted from the monthly reports prepared by the CBDs that are submitted to the Evaluation and Research Unit (ERU) at the Head Office. CBDs are expected to record and report only those visits in which oral contraceptives are distributed. Consequently, no information is available on the number of visits undertaken for other purposes, such as those in which clients are counselled about family planning but do not accept to use the pill, or when clients are supplied with condoms only, or when clients are referred for a clinical contraceptive method. Moreover, CBDs do not record those visits in which maternal or child health issues are discussed or information on sexually transmitted infections (STIs) or HIV/AIDS is provided. Thus, this performance measure captures only a part of the outputs being produced by the CBDs.

Data on the total number of visits for new and revisit pill clients were available for the period 1987 to 1999 (see Figures 1 and 2). As both graphs clearly show, there has been a persistent downward trend in the number of both types of visit made. Throughout the reporting period the ratio of re-supply to new client visits has been very high (about 95:5). There has even been a slight decrease over time in the proportion of all visits that are made for new clients from 5.8 percent in 1987 to 3.8 percent in 1999.

\section{Figure 1 Total number of new pill acceptors per year for the CBD program}

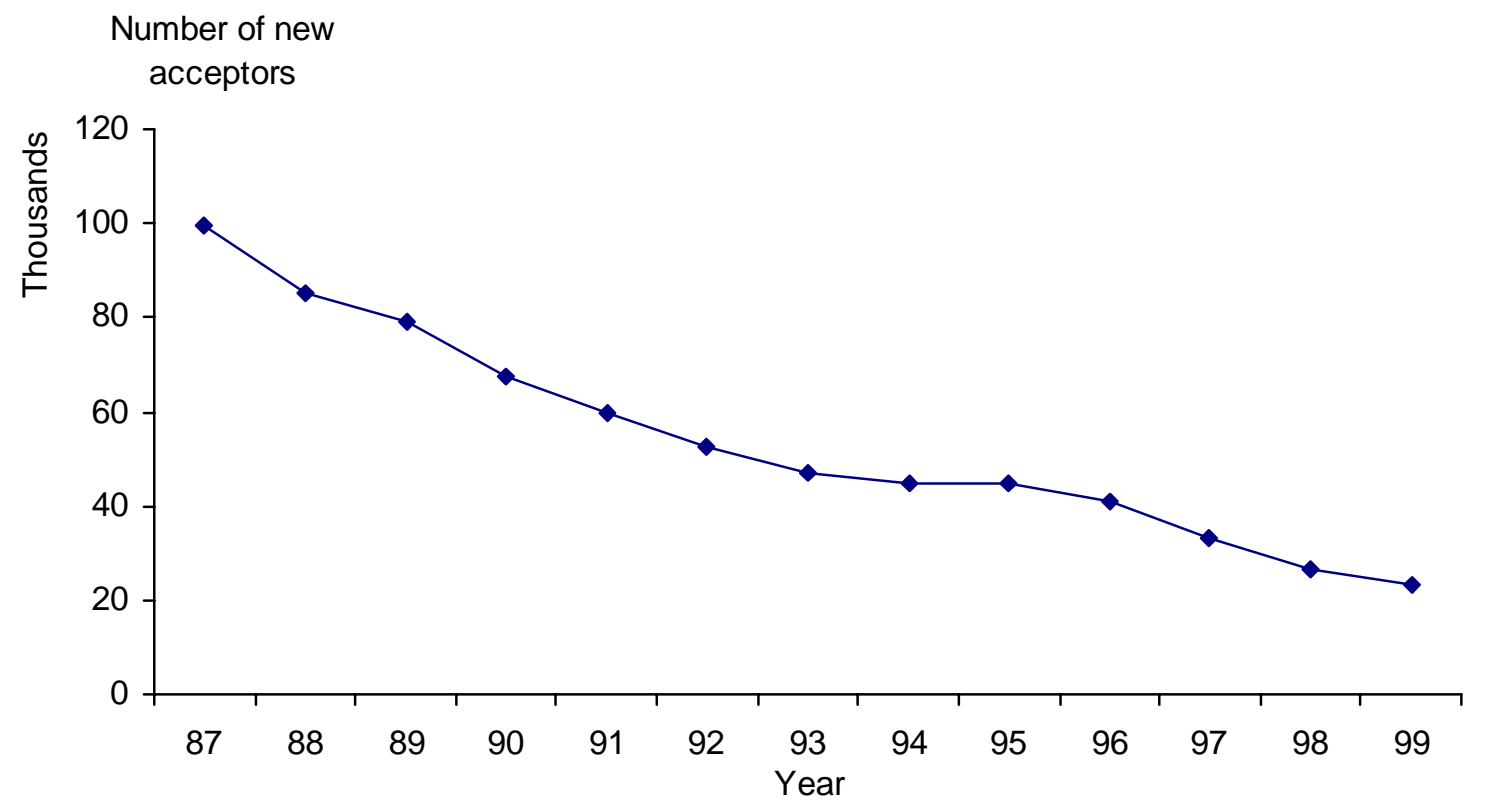


Figure 2 Total number of pill re-supply visits made per year

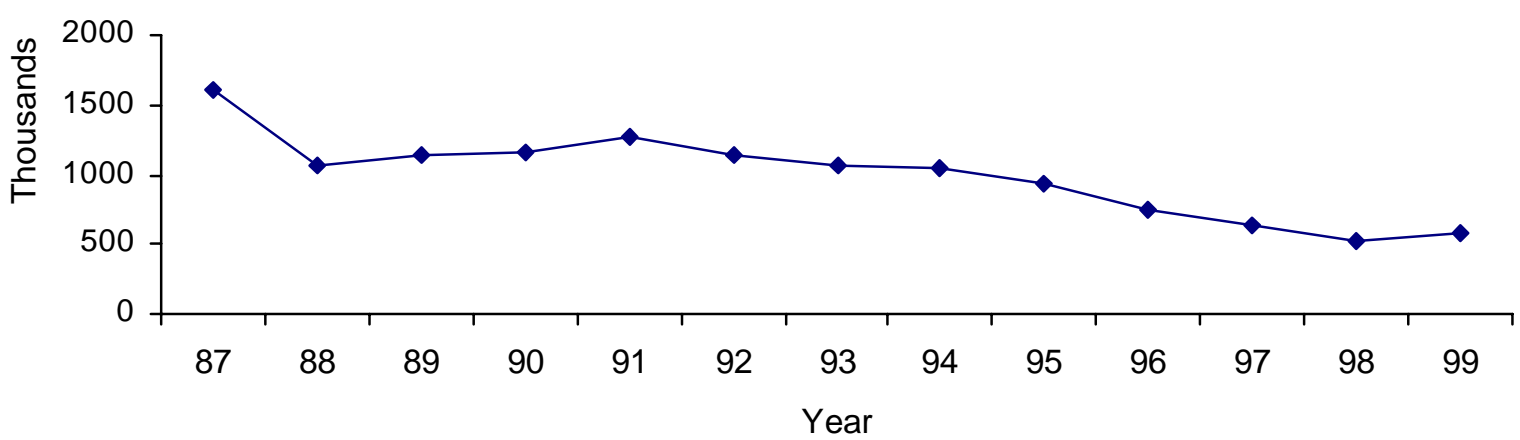

These data provide an indication of the overall performance of the programme over time, but do not measure the average productivity of the agents themselves. Figure 3 describes agent productivity for 1998 (the last year for which complete data were available) using the mean number of pill-related visits (for both new and re-visit clients) per CBD by province. The average number of visits for all CBDs was 918 clients (more than three per working day), but there are large variations by province. For example, CBDs in Mashonaland East made more than three times as many visits than the CBDs in Matabeleland South.

Figure 3 Average number of pill-related visits per CBD by province (1998)

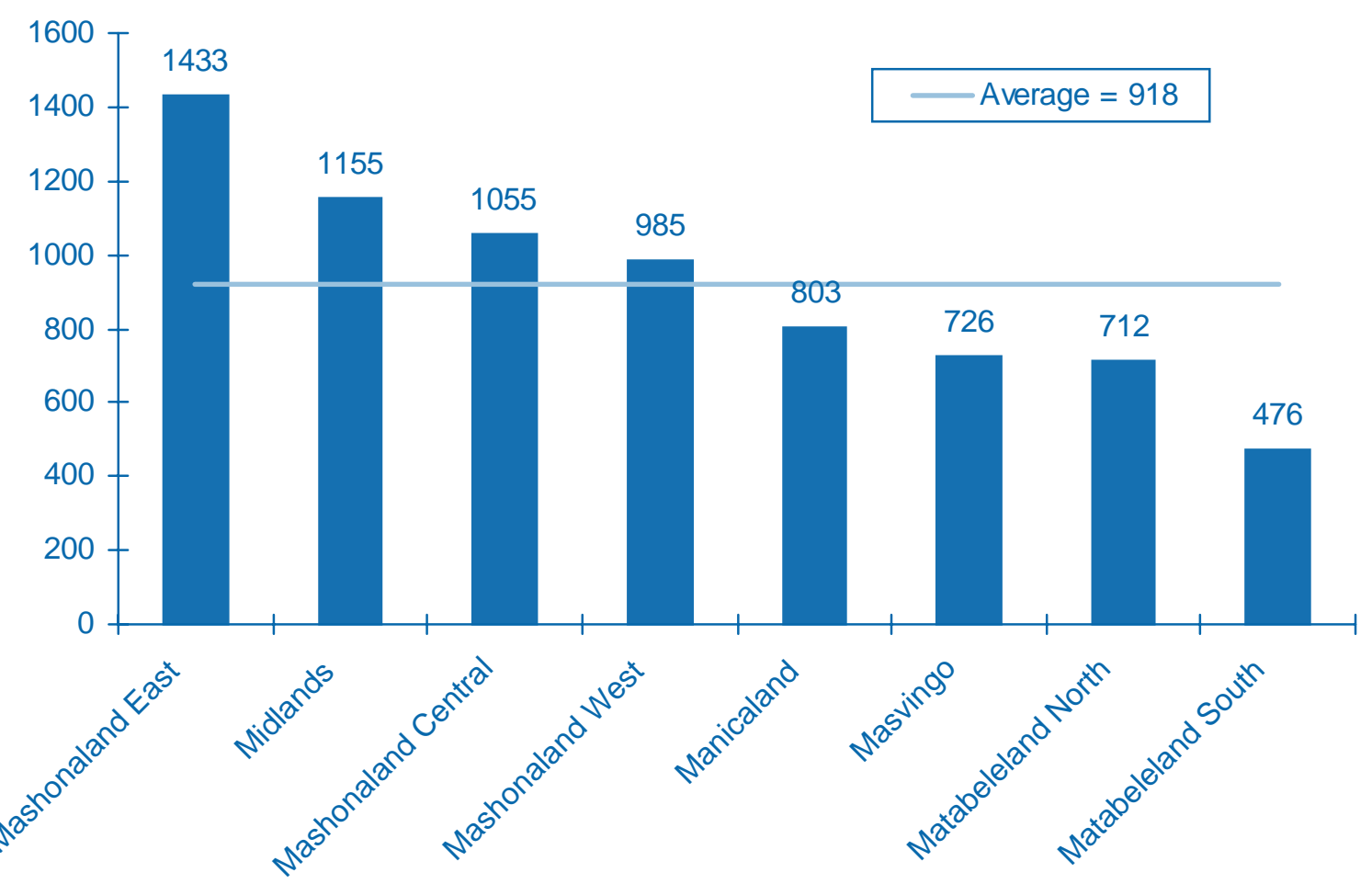


Preliminary data for 1999 showed that the average number of clients visited by each CBD had increased to 1,023 clients, with female CBDs making 1,077 visits compared to 888 being made by male CBDs. The increase in 1999 seems to be due to a rise in the number of resupply visits and not new pill users recruited.

\section{Couple Years of Protection (CYP)}

Although CBDs provide pills, condoms and spermicides, only the distribution of pills and condoms are recorded. The numbers of pills and condoms distributed were converted to CYPs using ZNFPC's conversion factors of 13 and 100 respectively. As can be seen in Figure 4, and as would be expected with the decrease in numbers of pill users served, there has been a decline in the amount of CYP generated by the programme. The proportion of CYP provided by condoms relative to that provided by pills has remained fairly constant over time.

\section{Figure 4 Couple Years of Protection generated per year}

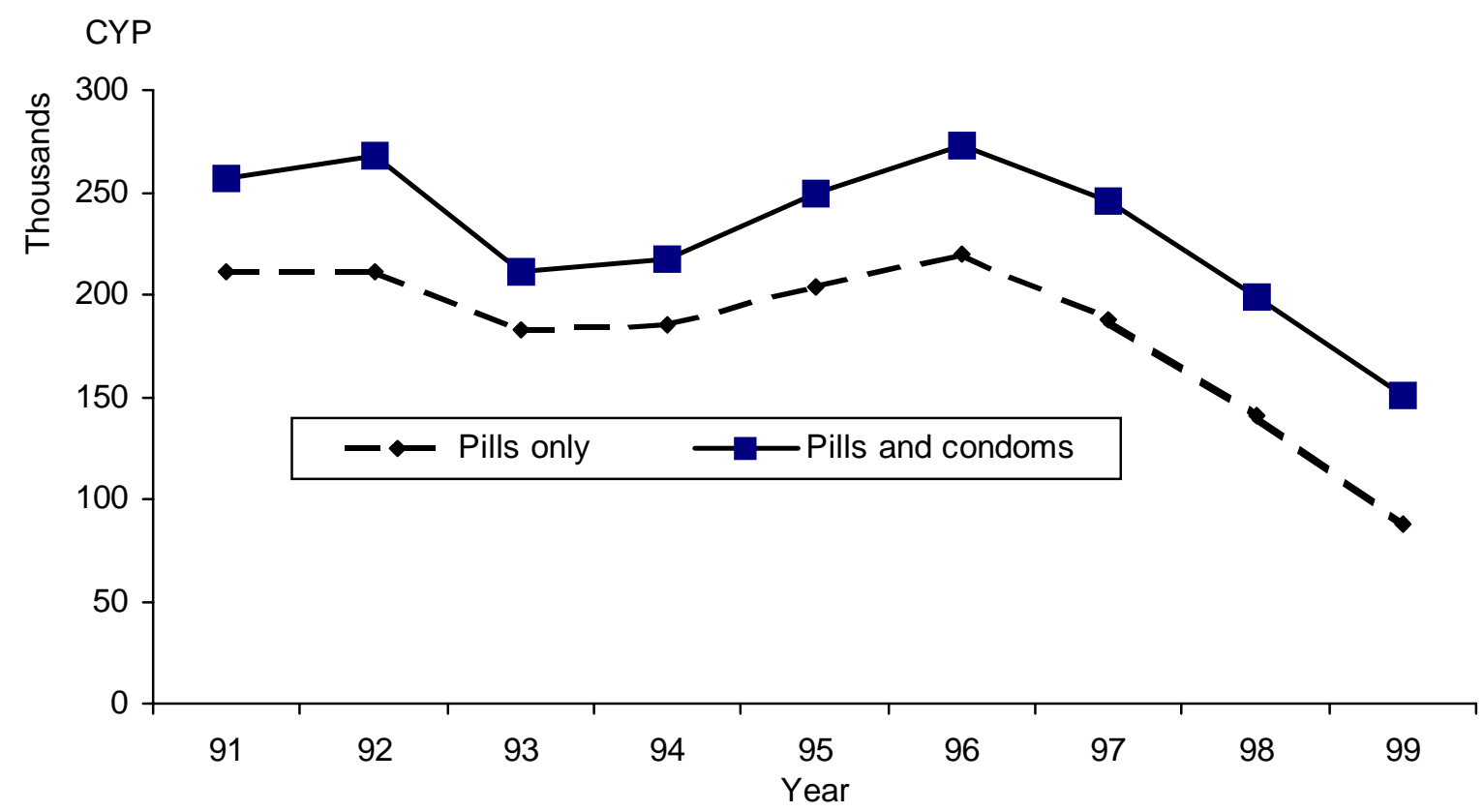

Figure 5 describes the average CYP provided per CBD by province for 1998 . This indicator shows a slightly different distribution pattern, in that the number of CYP per CBD generated are highest in Masvingo, whereas the average number of pill visits was highest for Mashonaland East. This may reflect differing patterns of contraceptive use in the provinces. Matabeleland North and South are again the two poorest performing provinces. 
Figure 5 Average Numbers of CYPs per CBD by Province (1998)

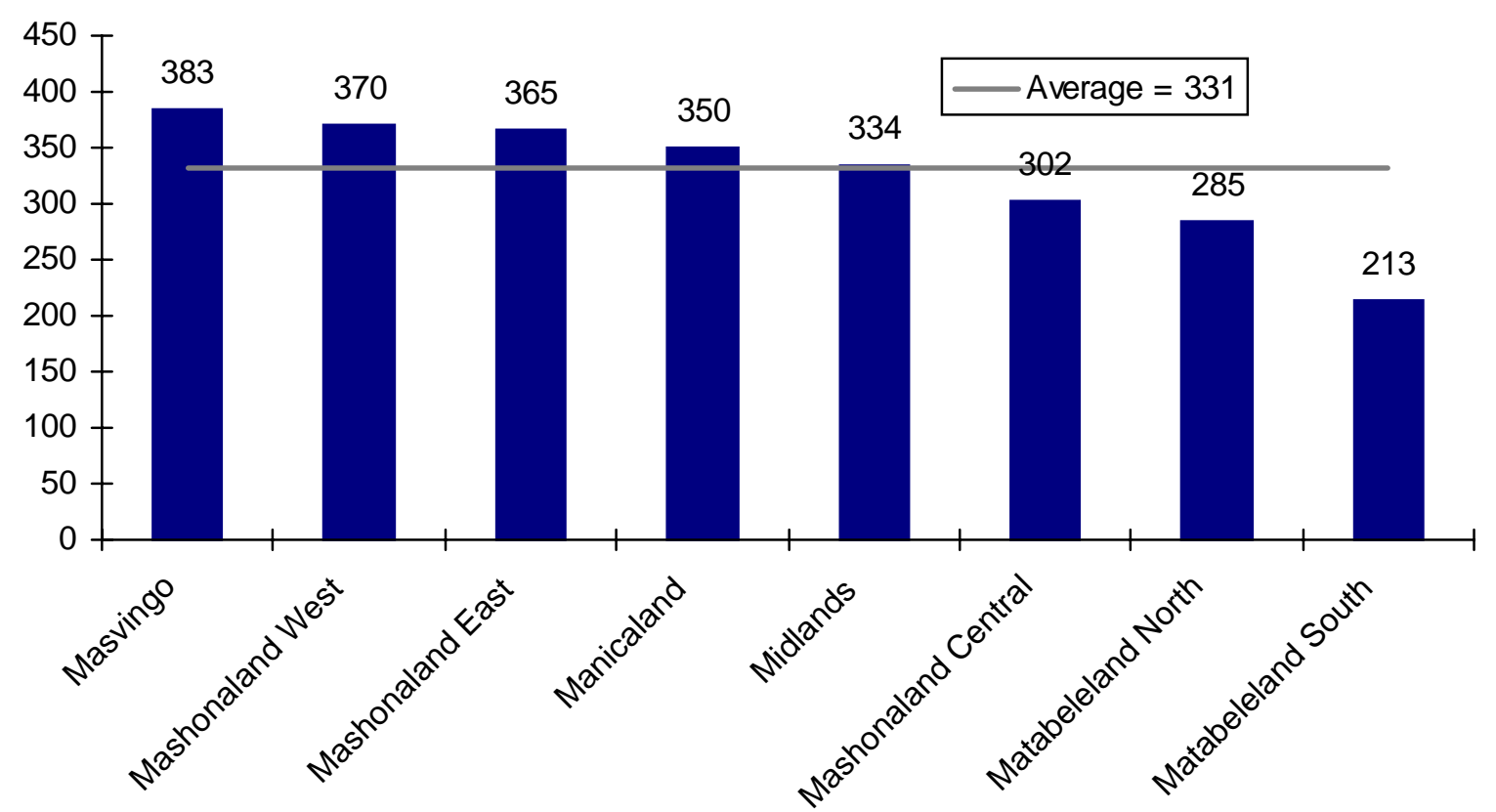

For pills and condoms combined, the performance was much lower in 1999 than in 1998, with female CBDs averaging 256 CYPs and male CBDs 220 CYPs. The averages for CYPs from pills only had decreased significantly (to 158 for female CBDs and 120 for male CBDs), although the CYP from condoms was similar to that of 1998, with an average CYP of 101 for females and 100 for males.

Both of these performance indicators show an overall decline in the number of pill users supplied and protection provided against pregnancy by CBDs over time. They also indicate significant performance differences by province. These findings are consistent with those from the Zimbabwe DHS that showed the contribution of the ZNFPC CBD programme to overall contraceptive prevalence to have declined from 25 percent in 1988 to 18 percent in 1994 and to only six percent in 1999. The decline in the contribution of the ZNFPC CBD program (CPR) in the country over this period has occurred despite the steady increase in the national CPR for modern methods. Over the same period the national CPR for modern methods increased from 27 percent to 50.4 percent.

\section{Possible Reasons For Declining Performance}

Several arguments can be advanced for the observed decline in the contribution of the ZNFPC CBD programme to family planning use in the country. At the beginning of the programme, CBDs were located in areas that were under-served by static public health facilities. The situation has changed significantly over time as many public health facilities have been built and are now providing family planning services in these areas. In addition, many other suppliers of family planning services have emerged, such as non-governmental organisations 
(NGOs), a social marketing programme and private voluntary organisations (PVOs), thus reducing proportionately the share contributed by the ZNFPC CBD programme.

A decline in contribution to the national contraceptive prevalence rate is not necessarily a bad sign for the ZNFPC, but only if other organisations are increasing their contribution, and as long as its CBDs are performing at the same or higher levels as when the programme began. A more serious concern, as demonstrated by these findings, is that its CBDs performance has declined steadily and seems to be continuing to decline. Why is this happening, and what are the implications for the future directions of the programme? A number of reasons suggest themselves.

When the CBD programme started, the national family planning programme was strongly promoting the use of the oral contraceptive pill. This was because the injectable Depo Provera was perceived to have been used by the colonial government as a means to control the African population, and as such the independent government did not want to be seen to be perpetuating this. However, there has been a shift in contraceptive use patterns over the last few years. The proportion of women using modern methods who use the pill has dropped from 85 percent in 1984 to 70 percent in 1999, whereas over the same period the proportion of women using long-term methods (mostly the injectable) has doubled from 12 percent to 24 percent.

As ZNFPC's CBDs do not provide long-term methods, their productivity may have suffered because they cannot directly meet the changing needs of their clientele. This may also explain why they are now undertaking proportionately less visits to new pill clients than to re-supply clients. Moreover, CBDs do not report on the number of clients referred for long-term methods. And so even if they are spending more of their time assisting clients to choose and obtain a long-term or permanent method, they are not getting credit for it because of ZNFPC's own record-keeping reporting system.

In addition, CBDs are expected to provide other reproductive health and primary health care services, but again these potentially time-consuming activities are not reported. If CBDs are spending more of their time on these activities than they used to and these activities are not recorded and reported, then it is unsurprising that their productivity, if measured solely in terms of contraceptive pills, is appearing to decline.

Another reason for declining productivity could be that the mean age for CBDs currently employed by ZNFPC is 43 years. The majority have worked for the programme for more than ten years, and only 22 percent of them have completed secondary school. The decline may, therefore, be a partial reflection of the difficulties that these older and less educated CBDs have in reaching out to the younger and more educated clients who may well be interested in pill use.

ZNFPC recently revised its service provision policies in 1995 to allow CBDs to provide up to six cycles of pills to clients. The other change introduced by the ZNFPC in 1998 was the introduction of a service charge for dispensing contraceptives. Both changes are capable of reducing the number of visits undertaken by the CBDs, either because of fewer re-supply visits or because of reduced demand. However, as the decline in new and revisit clients started well before these changes were introduced, decline in productivity cannot be attributed to them. 
It could also be argued that the CBD programme has achieved its original objective of raising awareness about and use of family planning, and that knowledge and use are now at a level beyond which a CBD programme's contribution becomes negligible and less cost-effective. Few other CBD programmes in the region operate in similar situations, and so it is hard to draw such a conclusion in reference to other experiences. 


\section{QUALITY OF SERVICES}

Although quality of care is best measured through methods such as observations of clientprovider interactions, use of mystery or simulated clients, and/or client exit interviews, it was not possible to use any of these methods, and so only information from the FGDs is available. A more rigorous assessment of the quality of service provided by CBDs, as well as in clinics, can be found in the 1996 national Situation Analysis study (Dube et al, 1998).

Both women and men reported that they were generally happy with the services provided by the CBDs. They felt that when CBDs approach a potential family planning client they provide this person with information on all family planning methods, their advantages and side effects, and that they assist the client to make an informed choice and allay any fears. Continuing family planning users reported that getting services from a CBD at home was much better than making visits to the clinic or hospital. At a clinic, there are generally long queues, nurses are busy with sick patients, and they have little time to explain how to use family planning methods and/or to allay fears and correct any misconceptions. Also, when clients visit the clinics they often have to use a bus, which greatly increases their costs of obtaining the services compared to when they get these services from the CBD.

Privacy is an important element of quality of care. Clients do not like situations in which their family planning practice or concerns are discussed or known by others. Respondents suggested that CBDs did provide the necessary privacy and confidentiality, especially for women whose husbands or religious affiliations were against the use of family planning. For example, although the Apostolic Faith has a large following in Zimbabwe and is strongly against use of contraceptives, a significant proportion of women from this sect have been able to access family planning services confidentially through the CBD programme. Moreover, since the interaction between CBDs and their clients takes place in the home environment privacy for the clients is greatly enhanced. This factor may act against ZNFPC's interest in switching to the "depot" system, whereby the client comes to the CBD's home for services. However, the ZNFPC plans to continue with some door-to-door CBD program to serve clients like those from the Apostolic Faith.

There was a consensus that CBDs can provide contraceptives at all times. In the last few years, contraceptive stock-outs have been a common feature at clinics. Consequently, in areas where there are no CBDs, or in cases where clients are not prepared to pay the $Z \$ 7$ per cycle charged by a CBD, clients may have to travel long distances only to find that the clinics have no contraceptives. This increases some clients' appreciation of the CBD programme because it saves them time and money. Also, CBDs keep a record of their clients' contraceptive needs and so clients do not have to remember when to get a re-supply.

To the community, the CBD is viewed as a source of several health services, not just family planning, and this is viewed as a positive attribute. Although the quantity and quality of these services was not established, some FGD respondents said that they appreciated the effort that CBDs were putting into these additional services. 


\section{COST ANALYSIS}

\section{Programme Costs}

Costs were calculated for the year 1998, as it was the most recent year for which all data were available for a full year. The costs calculated included those for salaries and benefits of all provincial level staff, transportation expenses to oversee the programme, initial and refresher training of both CBDs and group leaders, and the costs of contraceptives.

\section{Labour Costs}

Information on the salaries and benefits of all provincial staff that work full-time on the CBD programme was obtained from ZNFPC's Personnel Unit. For staff who work only part-time for the CBD programme, the Personnel Unit estimated the proportion of time spent for each category of person.

In 1998, the programme spent a total of $Z \$ 37,590,375$ (equivalent to US $\$ 2,088,354^{1}$ ) on labour; Figure 6 shows that salaries and benefits of the CBDs account for over 75 per cent of all labour costs. There was very little variation in the distribution of cost across the provinces.

\section{Figure 6 Distribution of labour costs by personnel category}

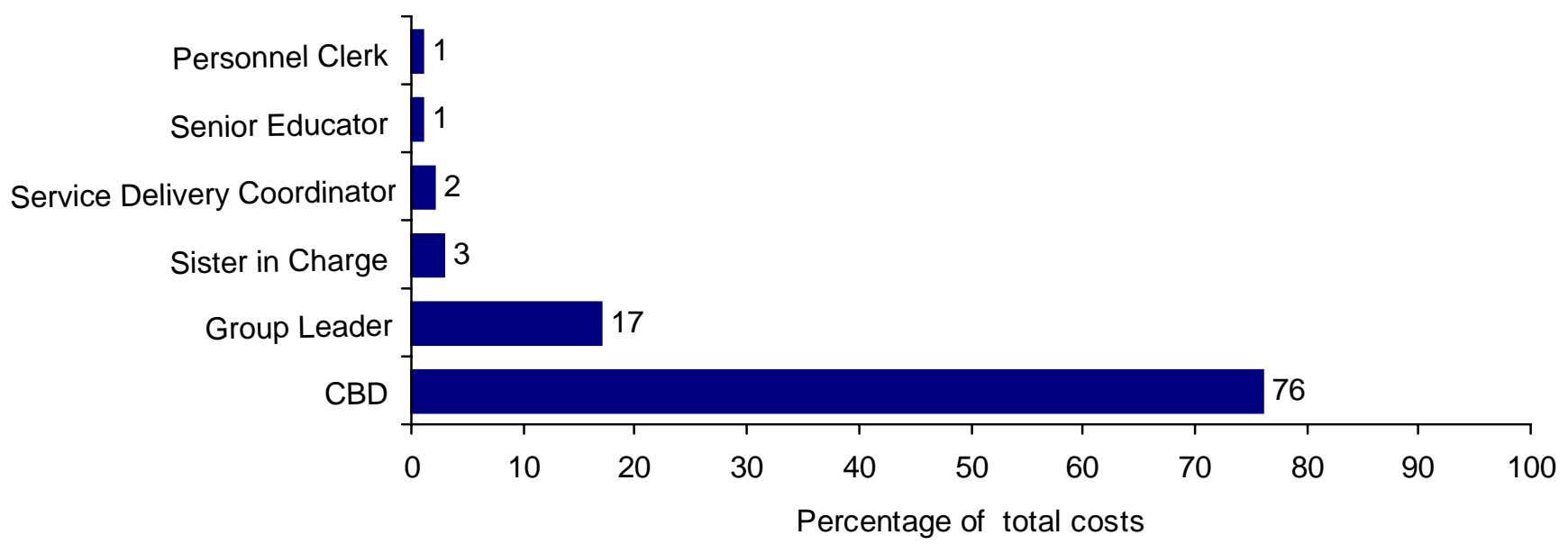

\section{Training Costs}

Annualised training costs for both CBDs and Group Leaders were estimated using information provided by the Training Coordinator based on costs of the most recent training courses conducted by the ZNFPC Training Unit. These costs included salaries and benefits of trainers; the costs for space, equipment and supplies to conduct the training, accommodations, per diems, travel to the training site and the costs, where applicable, of transportation expenses for trainers and trainees to make visits to households.

\footnotetext{
${ }^{1}$ The mid-1998 exchange rate was US\$1 = Z\$18
} 
The costs were annualised under several assumptions that included variations in the average time spent as a CBD and the actual and desired frequency of retraining. Information on the average time that a CBD was employed was available only for those CBDs currently employed and so the average length of employment or the average amount of time that the training yielded benefits had to be estimated. Training costs were also estimated for different frequencies of refresher courses.

Table 2 shows the average annualised training costs for CBDs and for the Group Leaders under the various assumptions. The scenario most similar to the existing situation gave an annualised cost of $Z \$ 4,893,626$ (US $\$ 271,868$ ). The highest costs, as expected, occur with shorter expected use of initial training and frequent refresher training. In these calculations, the middle values that represent "ideal" situations in that they combine high use of initial training and frequent refresher training were used.

Table 2 Annualised Costs for Training of CBDs and Group Leaders

\begin{tabular}{|c|c|c|c|c|}
\hline $\begin{array}{c}\text { Expected life of } \\
\text { initial CBD } \\
\text { training }\end{array}$ & $\begin{array}{c}\text { CBD } \\
\text { refresher } \\
\text { Training }\end{array}$ & $\begin{array}{c}\text { Expected life } \\
\text { of initial Group } \\
\text { Leader training }\end{array}$ & $\begin{array}{c}\text { Group Leader } \\
\text { refresher } \\
\text { training }\end{array}$ & $\begin{array}{c}\text { Total costs } \\
\text { (Zimbabwe } \\
\text { Dollars) }\end{array}$ \\
\hline 20 & Every 2 yrs & 10 & Every 2 yrs & $4,893,626$ \\
\hline 10 & Every 2 yrs & 5 & Every 2 yrs & $6,434,955$ \\
\hline 20 & Every 5 yrs & 10 & Every 5 yrs & $3,473,771$ \\
\hline
\end{tabular}

\section{Transportation Costs}

Each CBD is provided with a bicycle; GL have motorcycles and a mileage allowance for supervision. The costs of these were annualised using standard procedures. Each provincial supervisor has access to a car and the annualised costs of using this to supervise the programme were calculated using the average number of miles covered per year. The total annualised cost was Z $\$ 4,871,732$ (US\$270,652), with the largest proportion being for motorcycles and cars that are used for supervision. 
Figure 7 Transport Costs for CBD Programme

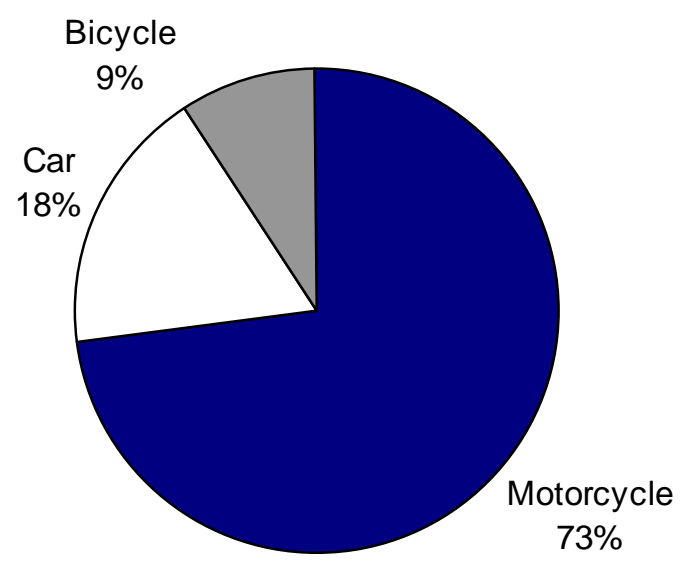

\section{Contraceptive Commodity Costs}

The cost of contraceptives was determined for the two types of pills distributed by the programme, and for condoms. These included the cost to donors of purchasing the contraceptives and of their shipment to Zimbabwe. The estimates of transporting the contraceptives from the stores to the provinces were not included in the analysis. The total cost of contraceptives was Z $\$ 12,157,287$ (equivalent to US\$675,405). Pills accounted for slightly more than half of the contraceptive costs, although they provided two-thirds of CYPs generated.

\section{Distribution of Costs by Component}

Figure 8 shows the distribution of the total annualised costs (Z\$59,513,020 or US\$3,306,279) among the major components. Salaries, and especially CBDs' salaries, account for the largest proportion of costs.

Since the training costs are only a small proportion of total costs, it is not necessary to simulate the different scenarios because they would make little difference to the distribution. These figures indicate that the CBD programme spends approximately $\mathrm{Z} \$ 100,000$ (US $\$ 5,500$ ) per CBD annually. 


\section{Figure 8 Total Costs of the CBD programme (Zimbabwe Dollars)}

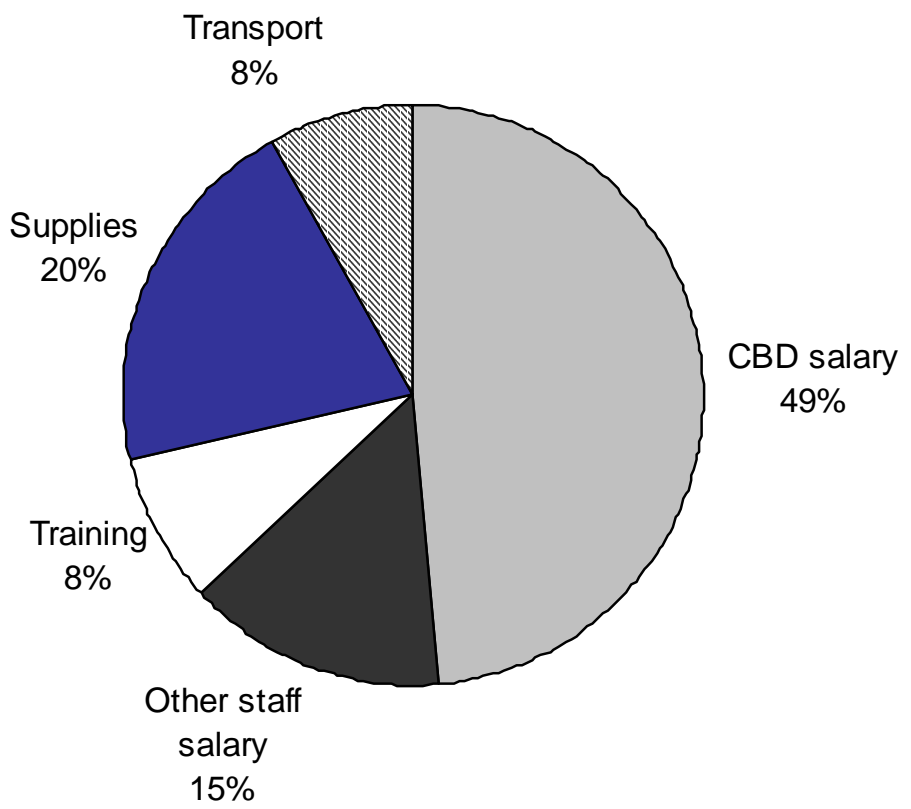

\section{Average Costs per Visit and per CYP}

The average cost per visit and cost per CYP by province were calculated by dividing the estimated annual costs for each province by the number of visits and the number of CYPs produced by each province in 1998 (see Figures 3 and 5 earlier). It is essential to bear in mind that, as with the measures of programme performance given earlier, these costs are per visit for new or re-supply pill clients only and for CYP generated by pills and condoms actually distributed. On average, each pill client visit cost Z\$108 (US\$6.00), and each CYP generated cost Z\$299 (US\$16.61). These figures are relatively high when compared with other CBD programmes in the region (Askew et al, 2000).

Table 3 describes the variation across provinces in terms of both measures. It is clear that the much higher costs per output for Matabeleland South push up the average per province, and so this figure needs to be interpreted with caution. Interestingly, these provincial variations mirror the distribution of outputs described earlier, in that the more effective provinces are also the more cost-effective. Thus Mashonaland East, Midlands, and Masvingo are the more effective and efficient, and Matabeleland North and South are the least effective and efficient. 
Table 3 Average cost (Z\$) per pill client visit and per CYP by Province (1998)

\begin{tabular}{|l|c|c|c|c|}
\hline Province & $\begin{array}{c}\text { Cost per } \\
\text { Visit }\end{array}$ & $\begin{array}{c}\text { Rank } \\
\text { Order }\end{array}$ & $\begin{array}{c}\text { Cost per } \\
\text { CYP }\end{array}$ & $\begin{array}{c}\text { Rank } \\
\text { Order }\end{array}$ \\
\hline All & 108 & & 299 & \\
\hline Mashonaland East & 43 & 1 & 169 & 2 \\
\hline Midlands & 54 & 2 & 185 & 5 \\
\hline Mashonaland Central & 61 & 3 & 214 & 6 \\
\hline Mashonaland West & 64 & 4 & 171 & 3 \\
\hline Manicaland & 79 & 5 & 180 & 4 \\
\hline Masvingo & 83 & 6 & 158 & 1 \\
\hline Matabeleland North & 86 & 7 & 216 & 7 \\
\hline Matabeleland South & 133 & 8 & 296 & 8 \\
\hline
\end{tabular}

The reasons for these differences were not explored in this review. However, it is known that Matebeleland North and South are more sparsely populated compared with the other provinces and so CBDs have to cover larger distances to recruit the few clients leading to the high costs per visit. Also, it is known that many males in these two provinces travel to South Africa in search of work, which has an effect on the demand for contraceptive services because of spousal separation.

In summary, the cost analysis shows that the major component of costs to the ZNFPC CBD programme is salaries and benefits, accounting for 63 percent of total costs. Output, measured either in visits to pill clients or in CYPs, varies greatly among the provinces, so that variations in costs per unit of output are primarily explained by variations in output. Because the number of CYPs generated fell sharply in 1999, while the number of pill client visits increased by a small amount, we may conclude that costs per CYP were higher in 1999 than they were in 1998, although costs per visit should have decreased by a small amount.

This cost analysis was limited by the fact that there was no information on the number or content of client visits that did not include distribution of oral contraceptives. Since other visits (for condom distribution, referral for other contraceptives, and other reproductive health services) could not be included in the calculations, the analysis over-estimates the cost per any visit made by a CBD. 


\section{POTENTIAL FOR IMPROVING SUSTAINABILITY}

The potential for improving the financial sustainability of the CBD programme was assessed by examining three approaches that the ZNFPC could take: increasing cost recovery; reducing the programme operating costs; and broadening and better documentation of the role of the CBDs.

\section{Increasing Cost Recovery}

Prior to 1998 , the CBD programme was charging a small user fee of $Z \$ 1.50$ for dispensing contraceptives to their clients. This user fee was increased to $Z \$ 7.00$ per cycle of pills in 1998, which translates into Z\$91 (US\$5) per CYP for the client. Although CBDs are supposed to charge for pills, they sometimes provide them for free if they believe that the client genuinely cannot afford to pay. Because of the HIV/AIDS epidemic, condoms are still distributed free of charge. The provincial office in the ZNFPC banks all the revenue generated by the CBDs from where it is transferred to the head office where it is then allocated to finance activities.

Data from 1999 were used to determine the performance of ZNFPC's cost-recovery strategy. The total revenue generated through contraceptive pill sales was Z\$7,754,180 (US\$430,788), representing 16.4 percent of the total costs of the programme. The average revenue generated per CBD from sales of pills was $Z \$ 13,580$ (see Table 4). Because of their superior ability to reach women, female CBDs generated significantly more revenue than male CBDs. There were large differences between provinces, with CBDs in Mashonaland West being able to generate over four times as much revenue as CBDs in Matabeleland South.

\section{Table $4 \quad$ Average revenue generated per CBD by sex and by province (1999)}

\begin{tabular}{|l|c|c|c|}
\hline \multirow{2}{*}{ Province } & Male & Female & Total \\
\cline { 2 - 4 } & $\mathbf{Z} \$$ & $\mathbf{Z} \$$ & $\mathbf{Z \$}$ \\
\hline Mashonaland West & 23,675 & 27,906 & 26,422 \\
\hline Mashonaland East & 11,552 & 23,533 & 20,318 \\
\hline Mashonaland Central & 14,507 & 18,754 & 16,961 \\
\hline Manicaland & 9,675 & 14,936 & 13,680 \\
\hline Midlands & 10,202 & 12,725 & 12,034 \\
\hline Matabeleland North & 6,443 & 11,364 & 9,839 \\
\hline Matabeleland South & 4,905 & 6,363 & 5,923 \\
\hline Masvingo & 5,916 & 14,664 & 7,156 \\
\hline National Total & 10,851 & 14,664 & 13,580 \\
\hline
\end{tabular}


This seems to be a promising start and a clear indication that pill clients are willing and able to pay for their contraceptives. Although introducing, and over time, increasing prices may result in fewer clients, this change will not necessarily result in lower contraceptive use in the country as the former CBD clients may seek contraceptives from other sources. If contraceptive use is unlikely to decline with increases in prices, ZNFPC needs to know for different price increases whether the gain in revenue from its remaining users is higher than the loss in revenue from clients leaving the programme. This information will allow the ZNFPC to select price increases that best achieve the goal of raising revenue without losing too many clients.

\section{Reducing Programme Operating Costs}

The second option for trying to close the gap between revenue and operating costs is to reduce the costs. Given that the largest proportion of costs is for CBD salaries and benefits, ZNFPC needs to find ways of reducing these costs while not significantly reducing the productivity of the CBDs. In the early 1990s, the ZNFPC developed and pilot-tested the "Depot Holder" approach as a variant on its standard CBD programme. The Depot Holders were paid a fixed allowance and their primary function was to re-supply existing clients with pills and condoms. By introducing this cadre of stationary, part-time agents, the regular CBDs are relieved of their re-supply function, thus creating more time for them to recruit new clients, follow-up on discontinuers, and carry out more information, education and counselling activities for family planning and STIs/HIV/AIDS. The Depot Holder project was successfully pilot tested in Manicaland province and proved itself as an approach that could potentially reduce costs (although this was never measured), but its operating costs need to be analysed and its replicability tested before it can be fully institutionalised.

\section{Broadening the Role of CBDs}

Although there has been a decline in the performance indicators described above, the costs to the programme are the same because the programme structure has not changed over time. In a situation where a programme cannot raise sufficient revenue to cover all costs, and cannot cut its operating costs, a further option is to try to make the CBDs more productive. Broadening the role of the CBD becomes opportune and may help to justify both the operating and sunk costs of the CBD programme.

The feasibility of broadening the roles of the CBDs was assessed through FGDs with clients already using CBD services, potential clients, men and community leaders, and through structured in-depth interviews with CBDs, programme managers, policy makers and other stakeholders. There was general agreement that STIs/HIV/AIDS are major problems in Zimbabwe and that adolescents and young adults are the groups most affected. Respondents from all groups agreed that CBDs have a role to play including:

- Providing information on STIs/HIV/AIDS

- Distributing condoms

- Identifying and referring individuals with STI symptoms to local clinics for diagnosis and treatment

- Providing supportive counselling to HIV/AIDS patients. 
However, respondents thought that CBDs are not effective in reaching the youth with this kind of information, and felt that parents can and should play a key role in addressing adolescent reproductive health issues. However, parents could only do this if they receive some training. It was suggested from the FGDs with clients and interviews with stakeholders that the CBDs could play a facilitative role by preparing parents to be able to communicate with their children on sexual and reproductive health issues. Another strategy proposed was that CBDs could play an advisory role to adolescents in the context of surrogate aunts and uncles, a practice that is already well accepted and entrenched in the Zimbabwe culture.

The Government of Zimbabwe, with support from USAID and other donors, has recently introduced Voluntary Counselling and Testing (VCT) for HIV infection as a response to the HIV/AIDS epidemic. In support of these VCT centres, respondents felt that the CBDs could:

- Inform their communities about the availability and location of VCT services

- Motivate people to go for VCT, especially before marriage and/or prior to getting pregnant

- Provide supportive counselling after testing.

Another role proposed was that of providing support for home-based care. Some CBDs are already doing some limited home-based care but their involvement is not yet approved and standardised by the ZNFPC. A major concern is that it can be very time-consuming and might take time away from their core role of providing family planning services. One feasible role could be for CBDs to identify clients who need home-based care services and link them to specialised community-based organisations that provide AIDS care and support, or to clinics for care and monitoring. Some respondents felt that although CBDs can provide this type of service, this may increase tremendously their workload. Interestingly, the CBDs interviewed did not see their potential involvement as a problem if their role remained that of providing information only.

The MOH\&CW programme managers felt that CBDs, as community workers, could assist with collection of community statistics on morbidity and mortality, and share these with the clinic for follow-up and programme planning. They also felt that CBDs should be used to follow-up clinic defaulters, including those for services other than reproductive health services, during their routine home visits. The ZNFPC programme managers, however, were concerned that CBDs may end up spending a lot of their time working on data collection and follow-up to the detriment of providing family planning services. The ZNFPC management felt that the Village Health Worker under the MOH\&CW could undertake this task as it is already in their job description.

Community members also suggested that CBDs could treat minor ailments before referring patients to the clinic for diagnosis, treatment and further management. Again the concern was that this would take time away from the CBDs' central function.

It should be borne in mind that the CBDs have already been trained and are expected to carry out a fairly broad set of activities that includes referring for clinical methods, informing and counselling community members of STIs and HIV/AIDS, and providing some other primary health care services. The issue of concern is that these activities are not currently reported, nor do they bring any revenue or increased contraceptive use, and so do not appear in any assessment of CBD performance. If they did, then ZNFPC and its donors would be in a better position to judge whether the CBDs were sufficiently cost-effective, or whether their roles could be revised and expanded. 


\section{DISCUSSION AND RECOMMENDATIONS}

\section{CBD Programme Staff}

The CBD programme has been operating for more than 20 years, and many changes have taken place in population settlement patterns, distribution and the facilities providing family planning services. ZNFPC needs to carry out a detailed review to determine the demand for community-based services in each of the catchment areas currently served. It also needs to review the criteria for selecting and defining catchment areas for new CBDs, if these are to be introduced. For example, CBD catchment areas should be population-based and not exceed 20 kilometres in radius. In areas where the need for CBD services has reduced significantly, ZNFPC should explore the possibility of re-deploying them as Depot Holders.

The CBD programme now has to provide services to a younger and more sophisticated clientele. In addition, if the ZNFPC wants to re-orient the roles of the CBDs to include reaching youth, identifying men with urethral discharge, and counselling clients for voluntary testing for HIV, these new roles may require individuals with different socio-demographic characteristics. Consequently, ZNFPC needs to review selection criteria with a deliberate effort to recruit younger and more educated agents, and with a higher proportion being single.

Related to this, ZNFPC managers felt that many CBDs are not following their workplans and absenteeism is rife. There is the concern that once CBDs have a job for life they have become lax. Moreover, some CBDs cover areas that are now well served by static clinics, but they cannot easily be retired or relocated because of their terms of employment. Furthermore, hiring CBDs on a permanent basis denies the community an opportunity to regularly assess and change their CBDs. Consequently, there is an urgent need to review the employment conditions of the CBDs.

Alternatively, CBDs could be paid a smaller basic salary, which they could supplement through commission from the sale of contraceptives. However, this strategy may conflict with ZNFPC's desire to broaden the CBDs' role as they would be more likely to spend time undertaking those activities for which they can earn a commission.

According to programme records, CBDs appear to be spending most of their time resupplying pills to continuing users, which does not seem to justify the amount of money spent on their salaries and benefits. CBDs claim, however, to provide other reproductive health services but without guidelines or training in the provision of such services and without getting credit during performance appraisals. Because of the limitations of their record keeping system, however, there is an urgent need for a time-motion study to better understand exactly how CBDs spend their time and what outputs they produce. This study is currently on going and the results will be reported separately. Thereafter, the ZNFPC will be able to review the job description and the roles and responsibilities for the agents, based on empirical evidence and will also enable ZNFPC to anticipate the potential effects of expanding the CBDs' roles.

Some programme staff (especially among the SICCs and GLs) are in positions whose tasks require higher levels of skills than they currently have. ZNFPC should review the recruitment criteria for these positions, and provide on-the-job training for the current positions holders. The current GLs are mostly former CBDs who have been promoted. They attend the District Health Team (DHT) meetings on behalf of ZNFPC, but their relatively low education level 
has resulted in problems with the $\mathrm{MOH} \& \mathrm{CW}$ programmes at district level. For example, the clinic staff at the MOH\&CW clinics expect help from the GLs with clinical problems a task that is above the training of the GLs. To strengthen this relationship, the ZNFPC needs to be represented at these meetings by more senior staff, such as the SICC or SDC.

The Zimbabwe Medical Board permitted CBDs to dispense oral contraceptives on condition that they do so under the supervision of a person with sufficient medical qualifications. The SICC supervises the CBDs to ensure that they comply with this requirement. The SICC position is a recent creation with responsibility for supervising and supporting the CBDs, and for ensuring good linkages with referral health facilities.

Although the SICC position requires a person with training in community nursing, most of the current SICCs do not have this background. The failure to recruit qualified nurses and to provide proper training for this position has resulted in some SICCs having a poor understanding of the CBD programme. ZNFPC needs to review the recruitment criteria for the SICCs, and to find a mechanism for equipping them with the necessary skills.

\section{Management Information System}

Service statistics are not adequately utilised or appreciated for planning, monitoring and forecasting contraceptive requirements at all levels of the programme. Consequently, ZNFPC (through the ERU) needs to ensure that, during basic and/or refresher staff training, time is allocated to collecting, recording, interpreting and utilising data at their own level. Moreover, the ERU should give feedback routinely to provinces on a quarterly basis instead of waiting to produce annual reports.

Restocking of contraceptive commodities was reported to be problematic. During a quarterly re-stocking visit, the GLs physically count the remaining commodity stocks of each CBD and reconcile this with the income generated. Thereafter, the CBDs, with assistance from GLs and the SICC, make forecasts of the quantities of contraceptives they will need for the next quarter. The re-stocking exercise is also used to discuss administrative issues with the CBDs, to update them on technical skills, and to assist them to resolve clients' problems. This is usually carried out in a three to four-hour session because each re-stocking team has to attend to more than one group of CBDs per day. The CBDs have to carry large volumes of contraceptives to the re-stocking sites and back to their homes using public transport.

It was suggested that GLs undertake re-stocking during their supervisory visits; the supervisory checklist would need to be revised to include this. The GL could then re-stock each CBD individually, which would free up time for the quarterly meetings to be used for discussing administrative matters and technical updates.

The Provincial Managers and GLs reported that a significant number of CBDs were unable to reconcile their contraceptive issues with the revenue generated. Whenever, this happens, the Provincial Manager makes the CBDs pay the difference. It was recommended that all staff be trained in contraceptive forecasting to minimise overstocking and contraceptive expiration.

\section{Training}

Since the beginning of the CBD programme, training has always been conducted centrally at the Spilhaus Family Planning Centre in Harare. This training was reported to be problematic because both classroom and field-based training are conducted in the English and Shona 
languages, which attenuates the benefits received by Ndebele-speaking trainees. Also, using one ethnic community for practical training does not expose the CBDs to social-cultural circumstances they are likely to encounter when they return to their communities. To address these concerns, ZNFPC needs to consider decentralising CBD training to its two regional training centres.

ZNFPC policy is that CBDs should attend update training at least once every two years, but due to limited financial resources, refresher training has been less frequent in recent years. To reduce costs and make refresher courses more meaningful, ZNFPC should decentralise them to the provincial and district levels. However, it may also be helpful for ZNFPC to first assess the effectiveness of retraining before embarking on a major exercise to ensure that it is worth the cost.

Although CBDs have been trained to provide information and counselling on STIs/HIV/AIDS to their clients, the CBDs, their trainers and supervisors reported that the time devoted to these topics during training was not adequate. Given the desire by the ZNFPC to strengthen this role, the Training Unit needs to review and strengthen the way these topics are taught by tailoring the training to the educational background and expectations from the CBDs and GLs.

Monitoring the effectiveness of the CBD training programme is the responsibility of the Training Unit, and is expected to be undertaken within six months through follow up visits to the trainees in the field. Due to financial constraints, however, the Training Unit has been unable to carry out these follow-up visits recently, and the SICC usually has to fill this gap. Decentralising training to the provincial level would help address this problem.

A significant number of GLs also reported that their basic training was not adequate, and that they had not had refresher training. Moreover, the SICCs are expected to supervise the GLs and CBDs, but many have not attended the basic CBD or GL training course. In addition, none of the current SICCs has been trained in logistics. Refresher courses to GLs and SICCs should be provided on a more regular basis.

\section{Supervision}

An intensive supervision system was possible to implement when the CBD programme was fully funded by the Government and donors. As funding became more limited, allowances were reduced, leading to a decreased number of supervisory visits. As a result of weaker supervision, absenteeism is now a common feature of the CBD programme that needs to be addressed urgently and effectively.

Although the number of supervisory visits has decreased, some programme staff and CBDs feel that they are still over supervised. For example, in some provinces, CBDs reported receiving supervisory visits from the SICC, the Senior Educator, the SDC and sometimes the Provincial Manager at different times, and sometimes with conflicting instructions.

Supervision need to be streamlined and co-ordinated, therefore, to avoid such confusion. For example, it was found that in some provinces the referral clinic staff and community leaders are monitoring and supervising the CBDs' activities. This approach reduces the number of visits that SICCs have to make and also the amount of travel that the GLs have to do. It also creates a sense of ownership by the community and clinics, but for the approach to be replicable ZNFPC has to be pro-active in formalising relationships with the local clinics and the community. 


\section{Relationship between the CBD Programme and the MOH\&CW}

Although the CBD programme was expected to have established linkages with the referral health facilities, these relationships appear to depend on the efforts of individual programme managers, GLs and CBDs. This is because ZNFPC as an organisation has not taken steps to formalise and standardise its relationship with the $\mathrm{MOH} \& \mathrm{CW}$ at the clinic level. Given that these linkages are a pre-requisite of the Zimbabwe Medical Council, ZNFPC needs to formalise them through guidelines that that detail the nature and obligations of both clinic staff and CBDs.

The relationship between ZNFPC and the MOH\&CW is good in those provinces where ZNFPC Provincial Managers regularly attend Provincial Health Team (PHT) meetings and share their work plans with MOH\&CW staff. However, as with the linkages between CBDs and referral clinics, these relationships are informal and dictated by personal relationships between the ZNFPC Provincial managers and the Provincial MOH\&CW staff.

At the district level, ZNFPC expects the GL to represent the CBD programme during the District Health Team (DHT) meetings. Other DHT members feel slighted that the ZNFPC has designated this lower level of staff to attend such important meetings, and so many GLs do not usually attend the meetings. This problem was found to be widespread. It is recommended that the SICC be given the responsibility of attending DHT meetings.

Some MOH\&CW managers reported that ZNFPC does not always allow its CBDs to interact with $\mathrm{MOH} \& \mathrm{CW}$ staff or to participate in $\mathrm{MOH} \& \mathrm{CW}$ activities when requested, and also that when the SICCs visit the referral clinics they are only concerned with family planning services. Although CBDs are expected to work closely with referral clinics and be technically supervised by clinic staff, in many provinces CBDs were no longer visiting the clinics regularly. The $\mathrm{MOH} \& \mathrm{CW}$ programme managers expressed concern about the quality of services being provided by CBDs if they are not being technically supervised.

Conversely, in provinces where CBDs do visit the clinics regularly, they have been allocated specific days to give health talks and provide family planning methods to the clinic clients. The clinic staff views the CBD as an additional staff member, which defeats the concept of the CBD approach.

The CBDs refer clients for methods requiring clinic facilities and clients with method-related problems, and clinic staff refer clients choosing to use oral contraceptive and condoms to the CBDs for re-supply and follow up. However, the current referral system does not allow for feedback either way.

ZNFPC charges for contraceptive commodities and increasing emphasis is placed on generating revenue, whereas the $\mathrm{MOH} \& \mathrm{CW}$ clinics do not charge for family planning services. This becomes problematic for both programmes when they refer clients for services and the expectations are different.

Moreover, the MOH\&CW staff felt that the clinic is the focal point for the provision of health services in any community, and so CBDs should see themselves as part and parcel of this system and attend clinic staff meetings for regular discussions. The MOH\&CW managers also felt that their clinic staff should be involved in the training and supervision of CBDs if they are going to provide technical support. Clearly the ZNFPC and MOH\&CW need to work together in formulating clear guidelines for their relationships at all levels, including representation, collaboration on clearly-specified activities, training, supervision, referral and feedback. 


\section{CONCLUSIONS}

The CBD programme in Zimbabwe was established almost thirty years ago to increase access to family planning information and services in under-served areas, and other studies have documented the programme's past contribution to this goal. The purpose of this assessment was to review the current functioning and performance of ZNFPC's CBD programme, with a view to providing guidance to ZNFPC senior management and the programme's primary external donor, USAID, for its future direction. The major findings from the study were as follows.

1. The productivity of the CBD programme, in terms of family planning clients visited and CYP provided, has been steadily declining over a number of years. Many possible reasons for this were identified, including the availability of more service delivery outlets in the agents' catchment areas, the increased use of contraceptive methods not provided by the CBD programme, and the aging over time of the CBDs and their consequent difficulty in reaching younger and unmarried clients.

2. CBDs have received some basic training in STIs and HIV/AIDS, and it is known that they do carry out several non-family planning activities in response to expressed needs from their communities. Moreover, their communities report that the quality of care provided is good, although this study was not able to confirm this through objective observations. A time-motion study was deemed necessary to gain a better understanding of what services CBDs provide and how they spend their time, and the results from that study will be reported separately.

3. The focus of the MIS is still on recording and reporting the CBDs' family planning activities only, however, and on service delivery only. Consequently it is virtually impossible for ZNFPC's provincial and senior management, and the programme's donors, to know the overall level of CBD productivity, and to know this on a routine basis. Because of this, it is also difficult to accurately calculate a cost-effectiveness ratio for the programme, although an estimate was made of the cost per pill client visit and cost per CYP provided. Reviewing and revising the MIS is clearly an urgent priority. However, this needs to be carried out after ZNFPC has completed its assessment of the future direction for the CBD programme.

4. This study indicated that the CBD programme could, potentially, play an expanded role in the country's fight against the AIDS epidemic beyond providing condoms to family planning clients. Such a role might include stepping up the agents' educational activities concerning HIV/AIDS and STIs (especially condom promotion), and in particular trying to reach youth of both sexes and males of all ages; improving health seeking behaviour of those with STI symptoms so that they are referred to competent medical facilities for diagnosis and treatment; and, where appropriate, supporting the newly established VCT centres through promoting their use and providing on-going support after testing.

5. If the programme is to redirect itself by broadening the agents' role along these lines, then a number of programmatic elements need to be addressed. Specific recommendations were made in the previous section, but in brief attention needs to be paid to the recruitment criteria for new CBDs, the training given to existing and new agents, the supervision system used, and the relationship between CBDs and the 
$\mathrm{MOH} \& \mathrm{CW}$ clinics to which their clients are referred. This latter issue will be especially important if CBDs are expected to become more involved in STI and HIV/ AIDS management.

6. Underlying any efforts to redirect the programme must be a consideration of the programme costs and their allocation between programme elements. The largest proportion of costs is to agent salaries, and so this is clearly the area that should be addressed most urgently if operating costs are to be reduced. Terms of service as well as salary and benefits levels need reviewing to look for ways of reducing costs without adversely affecting, and possibly with improving, agent performance.

7. Simultaneously, ZNFPC needs to look for ways to ensure a sustainable source of funding over the mid-term future. In addition to receiving funds from the Government of Zimbabwe and external donors such as USAID, ZNFPC should thoroughly explore increasing cost-recovery through charging for services and commodities. A study to explore price elasticity for family planning and other services would be a useful exercise to guide the development of service charges.

ZNFPC senior management has already taken on board most of these recommendations, and in August 2000 drafted a proposal for USAID for revising the programme so that CBDs have a broader range of responsibilities and the structure is modified to become more efficient. Agents will be expected to actively seek adolescents and men in their communities to offer them information about the full range of contraceptives, although with an emphasis on condom promotion. They will also be trained to provide more education, especially to men, on STI/HIV risk reduction behaviours, symptoms of STIs, and appropriate health-seeking behaviour when symptoms are suspected. Where available in the vicinity, VCT for HIV will be promoted and supported. CBDs will also be trained to give information on antenatal and postnatal care, to refer for infertility counselling, to refer for postabortion care, and to give information about reproductive tract cancers and counselling for menopause.

To achieve such a major change in the role of CBDs, ZNFPC will undertake a major revision of the CBD programme structure to address the weaknesses identified in this review. In addition to substantial refresher and update training, this will include revising the terms of employment for agents, widening the use of depot-holders to work in conjunction with regular agents, improving linkages with MOH\&CW clinics, improving contraceptive supply logistics, and revising the MIS and monitoring and evaluation procedures so that the programme's performance is fully measured in terms of this range of reproductive health activities. Underlying all changes will be a search for ways to ensure that costs are reduced and productivity improved. 


\section{REFERENCES}

Askew, I., J. Chege, N. Maggwa, B. Janowitz, R. Homan \& I. Kaboré. 2000. “CostEffectiveness Of Providing Community-Based Reproductive Health Services In SubSaharan Africa”. Paper presented at the American Public Health Association 128th Annual Meeting, Boston, Mass.

Dube, H., C. Marangwanda \& L. Ndhlovu. 1998. An Assessment Of The Zimbabwe Family Planning Programme: Results From The 1996 Situation Analysis Study. ZNFPC, Harare, Zimbabwe and Population Council, Nairobi, Kenya.

Maggwa, N., I. Askew, C. Marangwanda, S. Simba, H. Dube, R. Homan, B. Janowitz, A. Latif \& P. Mason. 1999. Demand For And Cost-Effectiveness Of Integrating RTI/HIV Services With Clinic-Based Family Planning Services In Zimbabwe. ZNFPC, Harare, Zimbabwe and Population Council, Nairobi, Kenya. 


\section{APPENDIX 1: ORGANOGRAM OF THE CBD PROGRAMME}

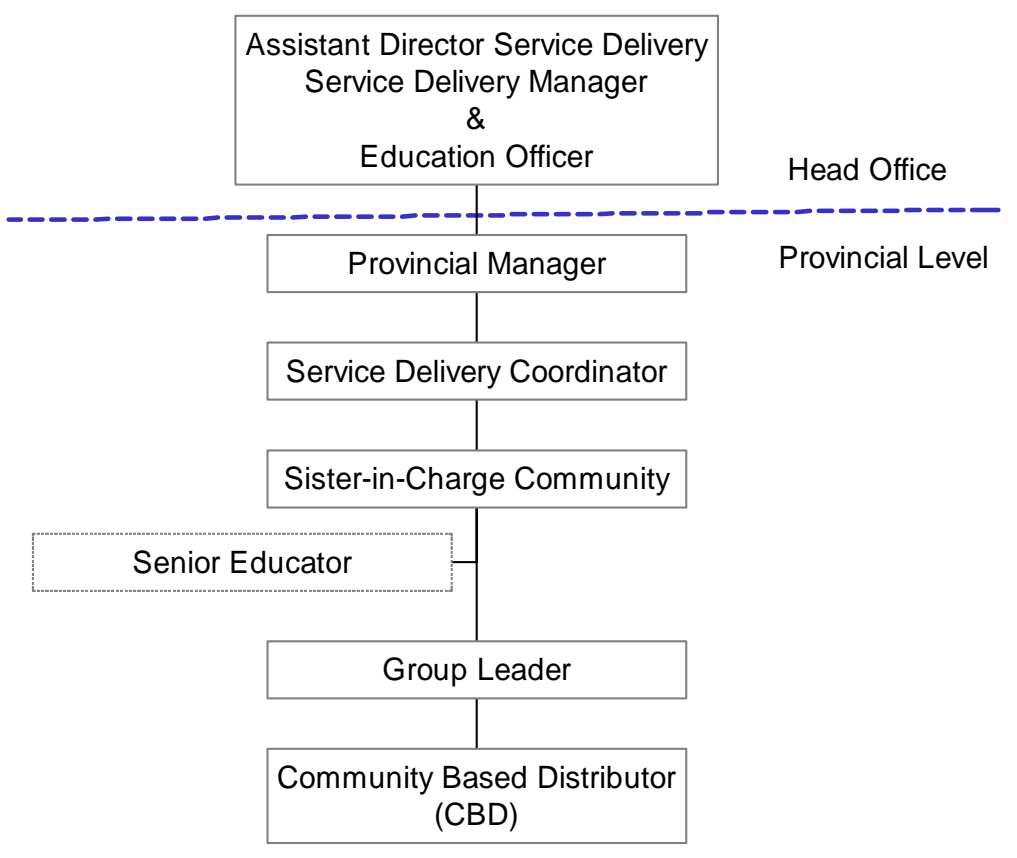




\section{APPENDIX 2: LIST OF PEOPLE CONTACTED}

\section{ZNFPC Head Office}

Mr. G. Tinarwo, Executive Director

Mrs. C. S. Marangwanda, Acting Director of Technical Services

Mr. T. Warinda, Acting Director Administration and Finance

Mrs. T. Nhliziyo, Assistant Director Service Delivery

Mrs. L. Botsh, Assistant Director Training

Mrs. F. Mhuriro, Assistant Director Information, Educational Communication

Mr. R. Hamadziripi, Human Resources Manager

Mr. A. Phiri, Programme Manager (Research)

Mrs. S. Simba, Service Delivery Manager

Mr. E. Hluyo, Education Officer

Ms. J. Mache, Training Officer

\section{ZNFPC Provincial Staff}

Mr. H. Soganile, Provincial Manager, Matabeleland North

Mr. N. Shoniwa, Provincial Manager, Mashonaland Central

Mr. F.E.W. Masakadza, Provincial Manager, Masvingo

Mr. I. Makozhombe, Provincial Manager, Mashonaland West

Mrs. S. Pfende, Provincial Manager, Mashonaland East

Ms. S. Sibanda, Provincial Manager, Matabeleland South

Mrs. P. Zimbizi, Provincial Manager, Midlands

Ms. E. Makoni, Acting Provincial Manager, Manicaland

Ms. A. Tengende, Service Delivery Coordinator, Midlands

Mrs. E. Muchirahondo, Service Delivery Coordinator, Matabeleland North

Mrs. R. Gandiwa, Service Delivery Coordinator, Masvingo

Ms. E. Chiundo, Service Delivery Coordinator, Mashonaland Central

Ms. T. J. Chabarika, Acting Service Delivery Coordinator, Mashonaland East 


\section{MOH\&CW Provincial Staff}

Dr. Bango, PMD, Matabeleland South

Dr. T. M. Chimbadzwa, PMD, Manicaland

Dr. L. S. Charimari, PMD, Mashonaland Central

Dr. W. Nyamayaro, PMD, Mashonaland West

Dr. Zishiri, PMD, Midlands

Dr. E. Mabhiza, PMD, Mashonaland East

Ms. S. Maketo, Acting PNO, Midlands

Mrs. Munodawafa, PNO, Manicaland

Dr. Hove, Medical Officer of Health, Manicaland

Mrs. Rwodzi, PNO, Mashonaland Central

Ms. J. Chitando, PNO, Masvingo

Mrs. Moyo, PNO, Matabeleland North

\section{Donor Agencies}

Ms. M. J. David, Programme Specialist-Health, USAID

Dr. P. L. Osewe, Programme Director-HIV/AIDS/STDs, USAID

Mrs. Todd, UNFPA

Ms. P. Darikwa, European Union 